\title{
Potential Drug Targets in the Pentose Phosphate Pathway of Trypanosomatids
}

Inês Loureiro ${ }^{1,2^{*}}$, Joana Faria ${ }^{1,2^{*}}$, Nuno Santarem ${ }^{1,2}$, Terry K. Smith $^{3}$, Joana Tavares ${ }^{1,2^{*}, \#} \&$ Anabela Cordeiro-da-Silva ${ }^{1,2,4^{\star}, \#}$

${ }^{1}$ Instituto de Investigação e Inovação em Saúde, Universidade do Porto, R. Alfredo Allen, 4200-135, Porto, Portugal;

${ }^{2}$ Parasite Disease Group, Instituto de Biologia Molecular e Celular, Universidade do Porto, R. Alfredo Allen, 4200-135, Porto, Portugal;

${ }^{3}$ Biomedical Sciences Research Complex (BSRC), The North Haugh, The University, St. Andrews, Fife Scotland. KY16 9ST;

${ }^{4}$ Departamento de Ciências Biológicas, Faculdade de Farmácia da Universidade do Porto, R. Jorge de Viterbo Ferreira 228, 4050-313 Porto

* These two authors contributed equally.

Address correspondence to Joana Tavares (Jtavares@ibmc.up.pt) or Anabela Cordeiro-daSilva, (cordeiro@ibmc.up.pt).

Keywords: Trypanosomatids, Treatment, Pentose phosphate pathway, Drug targets.

Originally published at Current Medicinal Chemistry, 2017, doi:10.2174/0929867325666171206094752. The published manuscript is available at EurekaSelect via

http://www.eurekaselect.com/openurl/content.php?genre=article\&doi=[10.2174/092986732566617 1206094752]. 


\section{ABSTRACT}

The trypanosomatids, Trypanosoma brucei, Trypanosoma cruzi and Leishmania spp, are causative agents of important human diseases such African sleeping sickness, Chagas' disease and Leishmaniasis, respectively. The high impact of these diseases on human health and economy worldwide, the unsatisfactory available chemotherapeutic options and the absence of human effective vaccines, strongly justifies the search for new drugs. The pentose phosphate pathway has been proposed to be a viable strategy to defeat several infectious diseases, including those from trypanosomatids, as it includes an oxidative branch, important in the maintenance of cell redox homeostasis, and a non-oxidative branch in which ribose 5phosphate and erythrose 4-phosphate, precursors of nucleic acids and aromatic amino acids, are produced. This review provides an overview of the available chemotherapeutic options against these diseases and discusses the potential of genetically validated enzymes from the pentose phosphate pathway of trypanosomatids to be explored as drug target candidates.

\section{INTRODUCTION}

Trypanosomatids belong to the Euglenozoa phylum, Kinetoplastida class, Trypanosomatida order, and Trypanosomatidae family [1]. They are a group of flagellated protozoa parasites found primarily in insects but a few genera have a digenetic life-cycle involving a secondary host such vertebrates, invertebrates or plants [2]. Interestingly, as these parasites emerge from the most ancient eukaryotic lineages, with branches deeper than those from the younger metazoan kingdoms of fungi, plants and animals, theythey possess many peculiar characteristics [3]. The single branched mitochondrion containing a unique mitochondrial DNA structure called kinetoplast,the unidirectional gene clusters that are polycistronically transcribed, a RNA polymerase I-mediated transcription of protein coding genes, a RNA transsplicing coupled to poly $(A)$ addition, an extensive RNA editing of mitochondrial mRNAs, a compartmentalisation of energy metabolism with the glycolytic pathway and other enzymes sequestered in the specialized peroxisomes called glycosomes, and a redox metabolism based upon a unique thiol called trypanothione, are some of the unusual characteristics of trypanosomatids [4-9]. Trypanosomatids of the genera Leishmania and Trypanosoma are causative agents of humans diseases, with considerable morbidity and mortality, affecting more than 27 million people worldwide [10]. Trypanosoma brucei, Trypanosoma cruzi and Leishmania spp, are the causative agents of Human African trypanosomiasis, Chagas' disease and Leishmaniasis, respectively. The geographic distribution of these diseases illustrates that they affect poor people living in the poorest regions of the world. In general the low access to ready diagnosis and affordable treatments, the absence of approved human vaccines and the use of the reference drugs for decades which induce severe side effects and leads to the emergence of drug-resistances makes these infections, high-impact neglected tropical diseases [10]. Since disease control relies mostly on chemotherapy, the search for new drugs becomes imperative.

In this review we will present the available treatment options for these diseases and discuss the potential of genetically validated enzymes of the pentose phosphate pathway to be explored as drug target candidates 


\section{HUMAN AFRICAN TRYPANOSOMIASIS (HAT)}

The causative agent and the clinical features. The causative agent of HAT, also known as sleeping sickness, is the extracellular flagellated trypanosomatid, T. brucei. There are three $T$. brucei subspecies, of which two infect humans, Trypanosoma brucei gambiense ( $T$. $b$. gambiense) and Trypanosoma brucei rhodesiense (T. b. rhodesiense), and one non-infective for humans, Trypanosoma brucei brucei ( $T$. b. brucei), therefore routinely used in laboratories [11]. Different to humans, Nagana disease in animals result from infections with $T$. congolense, T. vivax or T. b. brucei [12]. Gambiense HAT, caused by T. b. gambiense, is considered an anthroponotic disease with a minor role for animal reservoirs, while rhodesiense HAT, induced by $T$. b. rhodesiense, is a zoonotic disease, affecting mainly animals; humans are only accidental hosts. Unlike T. b. rhodesiense infections, in which nonhuman vertebrates are the primary reservoir, representing $<5 \%$ of HAT cases, $T$. $b$. gambiense infections represent $>95 \%$ of the cases [13]. T. b. gambiense infections are found in West and Central sub-Saharan Africa, while T. b. rhodesiense causes infections in East sub-Saharan Africa [11]. The geographic barrier of the two forms of the disease coincides with the Rift Valley, with T. b. gambiense and T. b. rhodesiense present at the west and east side of the valley, respectively [14]. Curiously, Uganda is the only country where the two subspecies co-exist, however there still remains a spatial separation between the subspecies, mainly due to the different climatic and vegetative conditions required by the two species [15]. Although some patients are occasionally reported outside Africa [16], 36 sub-Saharan African countries are still considered the endemic areas for HAT [14].

HAT etiological agent is transmitted through the bite of an infected tsetse fly (genus Glossina). Thirty-one species have been described, however in nature, infections are carried almost exclusively by Glossina palpalis (for T. b. gambiense; distributed in the Atlantic coast from Senegal to Angola), Glossina morsitans (for T. b. rhodesiense; located mainly in East Africa) and Glossina fuscipes (for both; present in central Africa from Cameroon and Congo to the Rift Valley) [14]. The mammalian host becomes infected through the bite of an infected tsetse fly vector that injects infective metacyclic forms, covered with a variant surface glycoprotein (VSG). Actually, T. brucei parasites change the composition of the insect saliva, in a way that increases vector-host contact frequency and enhances the probability of parasite transmission [17]. Once inside the host, the metacyclic trypanosomes proliferate at the site of inoculation and then transform into slender forms, as they are carried by the draining lymph nodes to the bloodstream, where they replicate by binary fission [18]. Notwithstanding, the skin has recently been identified as an important but overlooked reservoir of these parasites [19, 20]. More recently, the adipose tissue forms (ATFs) were identified, as both replicative and infective parasites. These forms reside in the adipose tissue, the third major reservoir of $T$. brucei in the host, which is likely to underlie the weight loss experienced by the patients [21]. When parasitaemia in the host increases, the long slender trypomastigotes (proliferative forms) release a soluble factor called stumpy induction factor (SIF), which triggers via a quorum sensing mechanism, parasites differentiation into short stumpy forms (nonproliferative forms) [22]. Stumpy forms, which do not divide, are crucial for limiting parasitaemia within the host, and subsequent differentiation to procyclic forms when taken into a tsetse vector. During vector blood meal, stumpy forms expressing VSG are ingested and primed to differentiate into procyclic forms. After multiplication in vector midgut, procyclic trypomastigotes initiate a migration, that takes them through the peritrophic matrix, along the foregut to the proventriculus, and from there onwards through the mouthparts, salivary ducts 
and finally into the salivary gland [23]. In the proventriculus, procyclic trypomastigotes undergo extensive restructuring, coupled to an asymmetric division to produce one long epimastigote and one short epimastigote [24, 25]. The short epimastigote, coated with alanine rich protein (BARP), attaches to epithelial cells following arrival in the salivary gland [26]. In order to complete the life cycle, the attached epimastigotes undergo a final transformation into free metacyclic trypomastigotes, along with the acquisition of the VSG coat, for evasion in the mammalian host [23].

Clinically HAT evolves in two stages. The first, known as early or haemato-lymphatic stage, is defined by the presence of parasites in the lymph and blood systems, while the second, named as late or meningo-encephalitic stage, is characterized by the active invasion of trypanosomes in the central nervous system (CNS). The duration of the first stage depends on the $T$. brucei subspecies and varies from few weeks to months in acute $T$. b. rhodesiense infections, or from several months to years in chronic T. b. gambiense infections [14]. After inoculation, the formation of a trypanosomal chancre, characterized by local erythema, oedema, heat, tenderness and a lack of any suppuration [27], arises in about $50 \%$ of rhodesiense infections, but is rarely formed in gambiense infections. After 3-4 weeks, the chancre usually heals with overlying desquamation, sometimes with altered pigmentation [11]. In T. b. rhodesiense infections, which present poor demarcation between stages, pancarditis with congestive heart failure, pericardial effusion, and pulmonary oedema can cause fatalities. In contrast, $T$. b. gambiense infections show a more insidious development [11]. The first stage is characterised by general malaise, intermittent fever, headache, severe pruritus with scratching, skin lesions, mobile or rubbery lymphadenopathies, oedema of the face and extremities and, to a lesser extent, myocarditis, splenomegaly or hepatomegaly [27]. In the second stage general malaise worsens, headaches become more severe and patient sleep pattern is altered. Later this stage culminates in coma, severe organ failure and eventually death [11].

Current therapeutic options. Since there is no vaccine against HAT and chemoprophylaxis is not recommended due to drugs toxicity, the only preventive measure rely on vector control. Vector control has been a way to limit mostly rhodesiense infections, although it was recently applied in gambiense HAT [13]. Vaccines are unlikely to be developed as a result of the different $T$. brucei defence strategies, like antigenic variation [28] and abrogation of B cell lymphopoiesis [29, 30]. In fact, several attempts have been made to come out with a vaccine, but this goal has never been achieved. The absence of an effective vaccine in combination with the knowledge about the obstacles in HAT vaccination field, strongly justifies an improvement of existing chemotherapy. HAT chemotherapy is still unsatisfactory, as it is lengthy, costly, toxic, ineffective against both stages of the disease and requires parenteral administration. If untreated, HAT is almost $100 \%$ fatal [31]. There are currently four licensed treatment regimes: pentamidine, suramin, melarsoprol and eflonithine. Nifurtimox-eflornithine combination therapy besides being used off-license, was placed on the WHO List of Essential Medicines [32].

Pentamidine. Pentamidine isethionate $\left(\right.$ Pentacarinat $\left.{ }^{\circledR}\right)$ is an aromatic diamidine used against first-stage disease caused by $T$. b. gambiense infection. Pentamidine is unsuitable for the treatment of advanced disease, in part due to serum binding and tissue retention properties that reduce blood-brain barrier traversal [33]. Four $\mathrm{mg} / \mathrm{kg}$ are given daily, or on alternate days by intramuscular injection for 7-10 days [34]. When given by intramuscular injection, site pain and transient swelling, abdominal pain and gastrointestinal problems, and hypoglycaemia (5-40\%) are the most frequently reported adverse events. The drug enters 
parasites principally via the adenosine transporter 2 (P2) aminopurine permease [35], however low and high affinity pentamidine transporters (LAPT1 and HAPT1, respectively) and a plasma membrane $\mathrm{H}^{+}$ATPases, $\mathrm{HA1}-3$, also contribute to uptake [36, 37]. Pentamidine action appears to be multifactorial possibly due to the binding to DNA [38]. It is also known to collapse the mitochondrial membrane potential, and inhibit the F1F0-ATPase [39]. Consequently, it is likely that the antitrypanosomal activity of pentamidine is the result of selective accumulation, leading to multiple deleterious effects, rather than effects on a specific 'diamidine target' [40]. It is noteworthy that confirmed pentamidine failures are rare, likely due to low drug-resistance. Recently through genome-scale RNA interference target sequencing (RIT-seq) screens, aquaglyceroporins (AQPs) loss-of-function was linked to melarsoprolpentamidine cross-resistance [37]. AQPs facilitate the transport of water and small neutral solutes across membranes in several organisms. T. brucei expresses three AQPS (TbAQP13) which are dispensable for viability and interestingly, for osmoregulation, yet making important contributions to drug-uptake, glycerol-transport and respiratory-inhibitor sensitivity $[41,42]$. AQP2 is responsible for the uptake of both pentamidine and melarsoprol, in the case of the former, most likely by receptor-mediated endocytosis and has been linked to clinical cases of resistance for both drugs [41]. This was an important finding since the crossresistance phenotype could not be explained based only in P2 and HAPT transporters.

Suramin. Suramin (Germanin®) is a sulphonated naphthylamine used for first-stage T. b. rhodesiense disease. Suramin is administered by intravenous injections every 3-7 days for 31 days $(20 \mathrm{mg} / \mathrm{Kg}$, with a maximum of $1 \mathrm{~g}$ per injection) [43]. Adverse drug reaction include acute and late hypersensitivity, nephrotoxicity, peripheral neuropathy, and bone marrow toxicity with agranulocytosis and thrombocytopenia [44]. This compound is selectively concentrated by trypanosomes through receptor-mediated endocytosis when conjugated with low-density lipoproteins (LDL) [45]. A high-throughput sequencing of a suramin-selected RNAi library identified a cohort of proteins contributing to drug efficacy [37]. In a proposed model, a $75 \mathrm{kDa}$ ISG (ISG75) acts as a major receptor for suramin delivering the drug into the degradative arm of the endocytic pathway. Suramin is delivered to the lysosome by either the serum protein carrier being cleaved by cathepsin-L upon reaching the lysosome, or by ISG75 being degraded at the late endosome. Once free, suramin may inhibit lysosomal enzymes and may also escape into the cytoplasm via the major facilitator superfamily transporter (MFST), resulting in inhibition of other cellular processes [46]. This large negatively-charged polyanion appears to inhibit non-specifically many positively-charged enzymes, so it is difficult to conclude which may be the determinant of drug action [47]. More recently, it was shown that this compound inhibits a number of glycolytic enzymes [43], such as pyruvate kinase by binding the ATP site and that clearly the sensitivity to suramin is dependent on the uniquely active endocytic apparatus in $T$. brucei bloodstream forms [48, 49]. Resistance to suramin was reported in the 1950s [43]. The mechanisms for suramin resistance are not yet elucidated but may involve changes in ISG75 and in proteins of the endocytic apparatus, including AP-1 (adaptin complex-1), GLP-1 (Golgi/lysosomal protein-1), EMP70 (endosomal membrane protein 70), MFST, p67 (major lysosomal glycoprotein), and cathepsin-L [37].

Melarsoprol. Melarsoprol (Mel B, Arsobal ${ }^{\circledR}$ ), a melaminophenyl arsenical synthesised in 1949, is still the most powerful trypanocide available to cure both stages of $T$. b. gambiense and T. b. rhodesiense HAT [50]. Importantly, is the only effective drug against late stage $T . b$. rhodesiense infections. It is usually administered intravenously and the recommended course is 10 days long with daily injections of $2.2 \mathrm{mg} / \mathrm{kg}$ [51]. Melarsoprol injections are extremely painful and toxic, and the most important reaction is a post-treatment reactive encephalopathy in $10 \%$ of patients, half of whom die, leading to an overall mortality of 
about 5\% [52]. Skin reactions, peripheral motoric, sensorial neuropathies and thrombophlebitis can also occur [53]. The parasites lyse rapidly when exposed to melarsoprol [54]. It is believed that melarsoprol is converted in the host to melarsen oxide, which is then transported by P2 transporter [55]. Melarsen oxide acts mainly through the formation of a stable adduct with trypanothione $\left[\mathrm{T}(\mathrm{SH})_{2}\right]$, known as MelT, which is an inhibitor of trypanothione reductase (TR), a central enzyme of the parasite thiol/disulfide redox balance [56, 57]. Additionally, melarsoprol also formed adducts with lipoic acid [58] and inhibits glycolysis [59]. In some T. b. gambiense HAT areas, melarsoprol treatment failures have already reached levels of $30 \%$ [60-62]. As mentioned above, the cross-resistance between pentamidine and melarsoprol was firstly associated with P2 transporter, once Tbat1 gene deletion and loss-of-function mutations were described in melarsoprol resistant strains generated in the laboratory [63-65], and the same mutations were also found in T. brucei spp. field isolates [66-68]. In addition, Tbat1-null trypanosomes were found to have lost the adenine-sensitive component of adenosine and melarsoprol-import [69, 70]. More recently, and as reported in pentamidine section, aquaglyceroporin 2 (AQP2) loss-of-function was linked to melarsoprol-pentamidine cross-resistance [37].

Eflornithine. Eflornithine (DL- $\alpha$-Difluoromethylornithine, DFMO; Ornidyl ${ }^{\mathrm{TM}}$ ) was developed in the 1970s [71]. Due to the unacceptable toxicity of melarsoprol, eflornithine is the first line treatment for the second stage T. b. gambiense disease [72-74]. It is administered intravenously. The high $\mathrm{IC}_{50}$ and the low half-life dictate the use of large quantities of the drug (nearly $4 \mathrm{~kg}$ for a $50 \mathrm{~kg}$ patient) for the treatment regime of 56 infusions over 14 days [53]. It is logistically difficult to deliver and to administer in the rural areas leading to a continued reliance on melarsoprol in impoverished areas. Adverse drug reactions include bone marrow toxicity leading to anaemia, leucopenia, and thrombocytopenia (25-50\%), gastrointestinal symptoms (10-39\%), and convulsions (7\%) [75]. Eflornithine mode of action is well understood as it irreversibly inhibits ornithine decarboxylase (ODC) an enzyme of the polyamines pathway [76, 77]. Eflornithine is only active against $T$. b. gambiense forms of HAT possibly due to a reduced rate of ODC turnover in this subspecie [78]. Identically the pronounced differences in ODC turnover rates between mammals and parasites explain drug selectivity [79]. American trypanosomes are totally refractory as they lack the molecular target. ODC inhibition by eflornithine leads to an increase in levels of ornithine, Sadenosylmethionine (AdoMet) and decarboxylated $S$-adenosylmethionine (dcAdoMet), and a decrease in putrescine, spermidine (Spd) and $\mathrm{T}(\mathrm{SH})_{2}$ [80-82]. As Spd conjugates with two molecules of $\mathrm{GSH}$ to form $\mathrm{T}(\mathrm{SH})_{2}$ which protects the parasite from oxidative stress, the decrease in Spd and consequently in $\mathrm{T}(\mathrm{SH})_{2}$ is therefore harmful for the parasites [9, 83]. Downstream of these metabolic changes, a generalized decrease in DNA, RNA and protein synthesis, including synthesis of VSG [84, 85] and morphological and biochemical changes like differentiation into stumpy forms can occur [86]. The fact that the trypanosomes are unable to undergo antigenic variation facilitates the death of the parasites by the host immune system [43]. Ultimately, the combination of distinctive parasite features, regarding the molecular target and polyamine metabolism, as well as the simultaneous interference in multiple cellular processes, render eflornithine a very successful drug. Resistance appears associated to a loss of the, amino acid transporter (TbAAT6) but whether this mechanism is found in field isolates awaits further investigation [33, 87-89].

Eflornithine-nifurtimox. The nifurtimox/eflornithine combination therapy (NECT) was advanced in 2009 [90, 91] for the treatment of late-stage T. b. gambiense, after showing equivalent to better efficacy than eflornithine alone in clinical trials [92]. NECT has not yet been tested against $T$. b. rhodesiense [93]. In combination, nifurtimox is given orally (daily 
dose of $15 \mathrm{mg} / \mathrm{kg}$, three times a day for 10 days) and the eflornithine infusions are reduced in frequency (daily dose of $400 \mathrm{mg} / \mathrm{kg}$ in 14 slow infusions, every 12 hours for 7 days). The administration of the combination therapy compared to eflornithine monotherapy is much easier to implement. NETC allows the use of lower doses of each drug, being logistically easier to transport due to the lower quantities required and the reduction in refrigeration costs [92]. NECT generates adverse events, mainly abdominal pain, vomiting and headache, however, the severity of these events is relatively low compared to previous treatments, and the majority of patients treated make a good recovery [90, 94]. With regard to resistance, a genome-scale RNAi library, to screen nifurtimox and eflornithine resistance, confirmed previous findings that nitroreductase loss-of-function is the major potential mechanisms of resistance to nifurtimox $[88,95]$.

Fexinidazole. Fexinidazole is in the development pipeline, being currently tested in a pivotal phase II/III comparative study in HAT endemic regions. If successful, it will provide patients with the first oral treatment for stage two sleeping sickness [96]. This compound, which came out from a screening of over 700 nitroheterocyclic molecules, is a 2-substituted 5nitroimidazole that exhibits in vitro and in vivo activity against both $T$. b. rhodesiense and $T$. $b$. gambiense [97, 98]. It is rapidly metabolised through oxidation, forming at least two pharmacologically active metabolites, fexinidazole sulfoxide and fexinidazole sulfone, which presumably account for much of the trypanocidal activity [97]. Although the mode of action is still not fully clear, it is likely that fexinidazole acts similarly to other 5-nitroimidazole drugs [99, 100].

\section{CHAGAS DISEASE}

The causative agent and the clinical features. T. cruzi is the parasite responsible for Chagas' disease. There are six discrete typing units (DTUs) of T. cruzi (Tcl-TcVI), which have distinct geographical distributions, extensive genetic diversity and differential virulence and pathogenic characteristics. Tcl, Tcll, TcV and TcVI are the main agents of human Chagas disease in the Americas, and all are capable of causing cardiomyopathies, however, only Tcll, $\mathrm{TcV}$ and TcVI have been so far associated to chronic digestive syndromes [101]. Despite the difficulty of an accurate determination of the number of cases, it is estimated 6 to 7 million chronically infected people worldwide and 10,000 to 14,000 deaths annually $[102,103]$. Chagas' disease is endemic in 21 Latin American countries [103]. Chagas was entirely confined mostly to Latin America, however nowadays it has spread to other continents, like United States, Canada, European countries, and some Western Pacific countries, due to a rise in population movements between Latin America and other continents [104-107], becoming a global health problem.

T. cruzi is transmitted to humans usually by the faeces of triatomine bugs. Parasites cannot penetrate intact skin and usually enter through skin microlesions originated from scratch the itching vector's bite. Similar, to other trypanosomatids, the $T$. cruzi life cycle comprises different developmental forms including epimastigotes and metacyclic trypomastigotes in the insect vector while in the mammalian host, bloodstream trypomastigotes and replicative intracellular amastigotes [108]. Mammals' infection occurs when infective metacyclic forms enter the mucosa and invade local reticuloendothelial and connective cells. Metacyclic trypomastigotes express an important adhesion molecule, GP82 (a surface glycoprotein of 82 
$\mathrm{kDa}$ ), which contributes to parasite internalization [109]. Inside the cytoplasm of host cells trypomastigotes differentiate into amastigotes that replicate by binary fission. When cells become full of amastigotes, they transform into trypomastigotes, bursting the infected cells. The released trypomastigotes then invade adjacent tissues, and spread via the lymphatics and bloodstream to distant body sites, infecting different cell types, like muscle and ganglion cells, where they undergo further cycles of multiplication [108]. The insect vector becomes infected when it ingests circulating trypomastigotes during a blood meal.

Chagas' disease comprises an acute and a chronic phase. The acute phase lasts between 1 to 2 months and usually passes unnoticed as the clinical symptoms are nonspecific and include fever, hepatosplenomegaly or lymphadenopathy. The inflammatory oedema at the entry site, known as chagoma in the skin, and Romaña's sign in the eyelid, consist of specific symptoms [110]. Acute myocarditis and acute meningoencephalitis can be occasionally seen in young children aged 1-5 years, being in most cases fatal and abnormalities in the electrocardiogram are observed in about $50 \%$ of cases which usually disappear later in the course of the disease [111]. Following the acute phase, the immune response induces a reduction of the parasite load but do not prevent the development of the disease [108]. About $60 \%$ to $70 \%$ of patients never develop clinical manifestations [112], while in the remaining, up to $30 \%$ of chronically infected people develop cardiac alterations and up to $10 \%$ develop digestive, neurological or mixed alterations, usually 10 to 30 years after the initial infection [103]. The lesions of chronic Chagas heart disease are focal or extensive myocardial fibrosis, resulting from myocardial cell destruction due to direct parasite action, inflammatory response, and neuronal involvement. The gastrointestinal manifestations consist of progressive enlargement of the esophagus or colon caused by chronic inflammation and destruction of parasympathetic neurons [101]. Among all complications, progressive heart failure $(70 \%)$ and sudden death $(30 \%)$ are still the most frequent causes of death in patients with Chagas' disease [113].

Current therapeutic options. Since there is no vaccine, Chagas' disease control programs in endemic areas have been focused on preventing parasite transmission through household insecticide application. Additionally, once triatomine bugs live mostly in rural endemic countries especially in poor housing conditions, hence improved housing can decrease the spread of the disease. In non-endemic regions, where vectors are absent, control strategies include preventing $T$. cruzi transmission from blood transfusion, organ transplantation, and mother to child, by screening donated blood and organs for the presence of parasites.

This disease is curable if treatment is initiated soon after infection, the current treatment options are limited to only two poorly tolerated nitro-heterocyclic drugs: benznidazole and nifurtimox. The toxicity of the available drugs [114], the emergence of benznidazole resistant $T$. cruzi strains showing cross-resistance to nifurtimox [115], and the lack of alternative medications, underline the imperative need to develop new strategies for chemotherapy. The promising azoles compounds, specifically posaconazole and the ravuconazole prodrug E1224, were disappointing as they failed in recent clinical trials, with treatment failure in patients reaching $70 \%$ to $90 \%$, as opposed to $6 \%$ to $30 \%$ failure for benznidazole-treated patients [112].

Benznidazole. Benznidazole, a 2-nitroimidazole (N-benzyl-2-nitroimidazole acetamide) is the reference drug against Chagas' disease and is administered orally. For acute treatments, 5 to $7.5 \mathrm{mg} / \mathrm{kg} / \mathrm{day}$ is used during 30 to 60 consecutively days, and divided in two or three daily doses. In the case of recent chronic infections, when the infection was acquired in the last 10 years, the treatment should be made $5 \mathrm{mg} / \mathrm{kg} /$ day during 30 to 60 days. 
In accidental infections, the treatment if started immediately, last for only 10 to 15 days. Cases of late chronic infections without clinical manifestation or with mild cardiac or digestive manifestations should be treated during 60 to 90 days with the purpose to reduce the evolution of Chagas disease to more severe forms, fact that has not yet been proven [114]. Benznidazole adverse reactions include hypersensibility, dermatitis with cutaneous eruptions (between 7th-10th day of treatment), generalized oedema, fever, lymphadenopathy, articular and muscular pain, depression of bone marrow, thrombocytopenic purpura and agranulocytosis, polyneuropathy, paraesthesia and polyneuritis of peripheric nerves [116]. The mode of action of this compound could involve covalent bond or other interactions of nitroreduction intermediates with parasite components [117] or binding to DNA, lipids and proteins [118].

Nifurtimox. Nifurtimox, another reference drug against $T$. cruzi infections, is a 5nitrofuran (3-methyl-4-(5'-nitrofurfurylideneamine) tetrahydro-4H-1,4-tiazine-1,1-dioxide). As benznidazole, nifurtimox is given orally. In acute phase treatment and congenital cases its recommended 8 to $10 \mathrm{mg} / \mathrm{kg} /$ day during 30 to 60 consecutively days, divided in two or three daily doses, while in initial chronic infections the treatment should be made with $8 \mathrm{mg} / \mathrm{kg} / \mathrm{day}$ during 30 to 60 days). The mode of action of nifurtimox involves generation of nitroanion radical by nitroreductases that, in the presence of oxygen, leads to the formation of reactive intermediates [119]. In trypanosomes the drug must undergo activation by nitroreduction, undertaken by NADH-dependent type I nitroreductases [95]. Recent evidences on the mode of action of nifurtimox showed that the formation of an open chain nitrile causes cellular death due to its interaction with a range of cellular targets [120].

\section{LEISHMANIASIS}

The causative agent and the clinical features. More than twenty Leishmania species and subspecies have the ability to cause Leishmaniasis [121]. The classification of Leishmania into subgenus Leishmania, which includes $L$. donovani, L. infantum, L. major, L. tropica, $L$. aethiopica, L. mexicana, L. pifanol and L. amazonensis species, and subgenus Viannia, that comprises $L$. braziliensis, L. guyanensis, L. panamensis and L. peruvianas species, was initially based on the vector gut parts colonized by the parasites, and later on was supported by DNA sequence-based phylogenetic analyses [122-124]. Some Leishmania spp., including Leishmania major, Leishmania mexicana, Leishmania amazonensis and Leishmania braziliensis, primarily cause tegumentary leishmaniasis, while others, like Leishmania donovani and Leishmania infantum disseminate to internal organs such as the liver, spleen and bone marrow causing visceral leishmaniasis. This later accounts for most of the deaths each year that are due to leishmaniasis [125]. Leishmania is prevalent in tropical and subtropical areas. This organism falls within two main groups, the Old World species (found in the eastern hemisphere; Europe, Africa and Asia), and the New World species (present in the western hemisphere; America). Species belonging to the subgenera of Leishmania are usually encountered in both Old and New Worlds, while others belonging to the subgenera Viannia are found only in the New World. Visceral leishmaniasis is caused by L. donovani in the Indian subcontinent and East Africa, and by L. infantum in other parts of Asia and Africa, Europe and the Americas. Tegumentary leishmaniasis can result by the infection of approximately 15 leishmania species: L. major, L. tropica, L. aethiopica and sometimes $L$. infantum in the Old World, and L. braziliensis, L. amazonensis, L. guyanensis, L. panamensis, L. mexicana, $L$. pifanoi, L. venezuelensis, L. peruviana, L. shawi, and L. lainsoni in the New World [126, 127]. Leishmaniasis is currently found in 88 countries, in which 72 are developing countries [128].

INSTITUTO DE INVESTIIGAÇÃO E INOVAÇÃO EM SAUUDE UNIVERSIDADE DO PORTO 
Interestingly, more than $90 \%$ of reported cases are located in 11 countries, India, Bangladesh, Nepal, Sudan, Brazil, Bolivia, Peru, Afghanistan, Iran, Saudi Arabia, and Syria [129]. This disease is associated with population displacement, poor housing, and lack of resources, therefore many cases are unreported. Nevertheless an estimated 1.3 million new cases and 20000 to 30000 deaths occur annually [130]. The geographical distribution of leishmaniasis has been increasing lately due to the incidence of HIV/Leishmania co-infections. It is estimated that HIV increases the risk of visceral leishmaniasis by 100-1000 times in endemic regions [131]. Moreover, the increased overseas travel, U.S. Gulf War veterans, the simultaneous encroachment of leishmaniasis and of HIV infection into rural areas have contributed to the increased appearance of leishmaniasis in developed countries $[132,133]$.

The natural transmission of leishmaniasis is mediated by the bite of an infected female sandfly upon blood feeding [134]. Within the order Diptera and the family Psychodidae, two sandflies genera, Phlebotomus in the Old World and Lutzomyia in the New World are capable of transmit the disease to man. About 70, from around 1000 known sandfly species, are competent leishmaniasis vectors [135] and only female sandflies can transmit the parasite as they need periodic blood meals in order to get the required nutrients for egg development. These vectors can be specific or permissive, whether they allow the development of one or several Leishmania species, respectively (Bates, 2008; Volf \& Myskova, 2007). For instance, Phlebotomus Phlebotomus papatasi and P. Paraphlebotomus sergenti, can only be infected by one species, whereas Lutzomyia longpalpis can transmit several parasite species [129]. Only on rare occasions, the vector requirement can be bypassed, such as in transplacental transmission, laboratory accidents or needle sharing [136-138]. In case of canine leishmaniasis, as parasites can be found in saliva, urine, semen and conjunctival secretions, as well as in blood, rare cases of horizontal transmission have been reported between dogs in the same household or kennel. Also rarely some ticks and canine fleas may also act as mechanical vectors [139].

During its life cycle Leishmania parasite goes through two main stages: one extracellular, the promastigote stage within invertebrate hosts (phlebotomine sandfly), and one intracellular, the amastigote stage in vertebrate hosts. During blood feeding by infected sandflies, infective non-dividing metacyclic promastigotes are regurgitated and delivered to the host, together with immunomodulatory parasite-derived proteophosphoglycans and various salivary components [125, 140, 141]. In the local environment, the parasites are then phagocytosed by one of several possible cell types, including neutrophils, macrophages and dendritic cells. Inside the cells, metacyclic promastigotes evolves into spherical intracellular forms, amastigotes, which undergo replication by binary fission. When too many amastigotes are present, the cells disrupt allowing reinfection of local phagocytes. Taken up by another sandfly, upon a blood meal, amastigotes are then converted into promastigotes in the midgut. The transmission cycle in then completed when procyclic promastigotes differentiate again into metacyclic promastigotes, which are located ready for transmission at the sandfly stomodeal valve (an invagination of the foregut into the midgut) [125].

Leishmaniasis is associated with a wide spectrum of clinical manifestations. The clinical outcome of a Leishmania infection depends upon a multifaceted association of factors among the three main players involved: hosts, parasites, and vectors. The disease has three different manifestations, cutaneous (CL), mucocutaneous (MCL) and visceral (VL), that differ in symptoms and consequences [142].

Cutaneous leishmaniasis. CL is the most common and most widespread. It is characterized by painful skin sores located at the site or within close proximity of a sand fly 
bite [129]. There is an emergence of one or several ulcer(s) or nodule(s) in the exposed areas of the skin. The ulcers are generally self-healing with no need for specific treatment, however they leave disfiguring scars [143]. The clinical manifestations are quite variable with regard to the formation of the ulcers, the level of inflammation and the healing time, reflecting 1) the diversity of Leishmania species that can cause CL; 2) the host status [144, 145]. CL has a worldwide distribution, but most cases ( 95\%) occur in the Americas, the Mediterranean basin, the Middle East and Central Asia. CL is endemic in 70 countries, but strikingly, more than two thirds of CL cases take place in 6 countries: Afghanistan, Algeria, Brazil, Colombia, Iran and the Syrian Arab Republic. Estimates point to 0.7 to 1.3 million new cases worldwide annually [130].

Mucocutaneous leishmaniasis. MCL is a severe form of CL, characterized by destructive ulcerations of the mucosa, extending from the nose and mouth to the throat cavities and surrounding tissues. This extensive tissue destruction is accompanied by an uncontrolled immune cell infiltration and inflammation [146]. Moreover, the consequent facial disfigurement profoundly burdens the patients with a lifelong social stigma. The current view is that the occurrence of MCL is determined by the host genetic background, but the severity of the pathology may be exacerbated by parasite-driven factors [147]. Almost $90 \%$ of the cases occur in South America, particularly in Bolivia, Brazil and Peru and is caused by species of the Viannia subgenera [130]. In contrast to the cutaneous form, self-healing is rare, the lesions are difficult to treat and potentially fatal due to opportunistic bacterial secondary infections [143].

Visceral leishmaniasis. VL is the most severe, with a mortality rate of essentially $100 \%$ if untreated. It is characterized by irregular bouts of fever, substantial weight loss, swelling of spleen and liver, and anaemia [129]. L. donovani is the causative agent of VL in Asia and East Africa, whereas L. infantum equally leads to visceral compromise but in the Mediterranean Basin and South America [135]. Differently, while dogs are the most important reservoirs of $V L$ caused by $L$. infantum, in the case of $L$. donovani, the disease is mostly anthroponotic [143]. Another striking difference is that $L$. donovani is capable of causing disease in people of all ages, although children and young adults are the most affected. In the case of $L$. infantum, small children used to be the main age group, however, as HIV (Human Immunodeficiency Virus)/L. infantum co-infections emerged, nowadays adults actually represent almost half of VL cases in Europe [130, 143]. Post Kala-azar Dermal Leishmaniasis (PKDL) is a resurgence of the visceral form, months or even years after treatment and is characterized by macular, maculopapular, and nodular rashes [129]. The cause, risk factors and pathogenesis of PKDL are largely unknown, although it has been associated with several host factors [148] and as drug related phenomenon [149].

Current therapeutic options. As antileishmanial vaccines are still under development [150], current leishmaniasis control strategies rely upon case management (detection and treatment), reservoir and vector control, and chemotherapy. Active case detection and surveillance, accompanied by preventing reinfection measures, through targeting the socioeconomic and cultural factors, should be implicated in the attempts to reduce disease transmission. With respect to reservoir control, infected dogs are most frequently treated with the drugs meglumine antimoniate, alopurinol, amphotericin B, or a combination of meglumine antimoniate and alopurinol. However, these therapies are the also used against human leishmaniasis and usually do not prevent relapse of the disease or eliminate parasite carriage. Similar to the above mentioned trypanosomatid diseases, new drugs and treatment strategies are necessary to achieve a consistent parasitological cure [151]. Sandflies eradication is widely put in practice by the use of chemicals, environmental management and personal 
protection [134]. Nevertheless, the major control strategy is still based on chemotherapeutic treatments which are expensive, toxic and associated with high relapse and resistance rates. The leishmaniasis chemotherapy depends on some factors including type of disease, parasite species and geographic location [130]. For the past seven decades, chemotherapy has mostly relied on pentavalent antimonials, the standard first line treatment for both visceral and cutaneous leishmaniasis, but the emergence of resistance has limited their usefulness. Alternative therapies, like amphotericin $B$ and its lipid formulation, miltefosine and paromomycin, are available but their use is limited due to toxicity or high cost [152]. Once all these drugs are parenteral, the discovery of effective oral agents is crucial [153].

Pentavalent antimonials. Pentavalent antimonials were developed in 1945 [154] and this family of compounds, represented by sodium stibogluconate (Pentostam $\AA$ ) and meglumine antimoniate (Glucantime $\AA$ ), remains the first line therapy against leishmaniasis in most of the world's regions, with few exceptions, like Bihar state [155]. ). The antimonialbased therapies have disadvantages that include the long-term treatment and parenteral administration under close medical supervision due to high toxicity. Their high toxicity represents an important limitation in the use of these drugs by pregnant women, the elderly, and individuals with cardiac disease, renal disease, or liver alterations [156]. These drugs are prodrugs that require biological reduction to trivalent antimonials for antileishmanial activity. The bioactivation can occur in the host cell or the parasite: glutathione, present in the cytosol of macrophages, cysteine or cysteinylglycine thiols, found mostly inside the host lysosomes, as well as trypanothione, the most abundant thiol in Leishmania parasites, can actively reduce SbV [157, 158]. Additionally, Sblll enters the parasites via aquaporin 1 (AQP1) [159] and Leishmania enzymes such as thiol dependent reductase 1 (TDR1) and antimoniate reductase have also been implicated in SbV bioactivation [160]. Despite the mechanism of action not being fully understood, Sblll is well established as the active species that ultimately leads to parasite death [161]. There is some evidence supporting zinc finger proteins and trypanothione reductase as possible molecular targets [162, 163]. Inclusively, by exposing the parasites to trivalent antimonials, an efflux of glutathione and trypanothione from promastigotes and isolated amastigotes was observed, suggesting an interference with the parasites' redox state [164]. Additionally, these drugs appear to inhibit parasite glycolysis and fatty acid $\beta$-oxidation, however no specific targets on these pathways have been identified $[165,166]$. Another possible mode of action is based on SbV's capacity to form complexes with ribonucleosides, which can inhibit purine transporters or directly interfere with the purine salvage pathway in Leishmania [167].

In the past few years, following the growing and alarming emergence of antimonial resistance in endemic areas, many studies have been conducted to dissect the molecular mechanisms. Inclusively, microarray technology and proteomic screening have been employed in order to elucidate these mechanisms [168-170]. Those include loss of AQP1 activity [159], extrusion of trypanothione/SbIII complexes by ATP-binding cassette $(A B C)$ transporters, sequestration of SbIII in vacuoles [171] or downregulation of MAPK1 that is a negative regulator of P. glycoprotein type efflux pumps [172]. Therefore, the mechanism of resistance is multi-factorial, including a decrease in uptake, an increase of efflux/sequestration and the modulation of the parasite thiol metabolism [173, 174]. Despite all these drawbacks, antimonial drugs remain highly effective in areas where resistance has not yet emerged [175].

Amphotericin B. Amphotericin B was originally developed as a systemic antifugal drug that targets ergosterol-like sterols. With ergosterol being one of the most abundant sterol in Leishmania promastigotes and amastigotes surface membranes [176, 177], amphotericin B treatment leads to an increased permeability and an influx of ions [176-178]. As mentioned 
above, due to the increased emergence of resistances to pentavalent antimonials in India, amphotericin B deoxycholate in a dose of $0.75-1 \mathrm{mg} / \mathrm{kg}$ for 15 to 20 infusions daily or on alternate days, produced cure rates of $97 \%$, is the drug of choice in this region, despite intravenous administration and its high toxicity requiring close medical supervision $[179,180]$. It causes adverse effects that include nausea, vomiting, fever, hypokalemia, renal failure, anaemia, leukoencephalopathy and heart problems [181]. The toxic events were substantially reduced by the emergence of amphotericin B lipid formulations. Even though, in many undeveloped countries or impoverished communities the use of lipid formulations was until recently impractical due to their high cost and the need of close monitoring due to the risk of serious, even fatal, side-effects [129]. Three amphotericin B lipid formulations are commercially available: liposomal amphotericin B (AmBisome $\left.{ }^{\mathrm{B}}\right)$, amphotericin $\mathrm{B}$ colloidal dispersion (Amphocil ${ }^{\circledR}$ ) and amphotericin $B$ lipid complex (Albacete $\AA$ ). AmBisome $\AA$ is the best tolerated [179] and it is the first-line treatment of visceral leishmaniasis in the United States and southern Europe, representing the treatment of choice for immunocompetent patients in the Mediterranean basin and the preferred drug for HIV/VL co-infection. In immunosuppressed patients a total dose of $40 \mathrm{mg} / \mathrm{kg}$ AmBisome $\AA$ spread over 38 days is recommended [182], however in immunocompetent individuals different dose regimens have been used [183-185] [183, 184, 186, 187]. Apart from the direct effect of amphotericin B on the parasites through formation of aqueous pores in the plasma membrane, AmBisome $\AA$ also appears to interact with the sterols in the membrane of macrophages, preventing Leishmania entry as well $[188,189]$.

A few cases of resistance have been reported but the underlying mechanisms are poorly understood [190]. Laboratory acquired resistance has been associated to ergosterol deficiency in the parasite membrane or the enzyme S-adenosyl methionine transferase, which is involved in the ergosterol synthesis [191, 192]. Changes in the plasma membrane sterol profile have also been reported in $L$. donovani clinical isolates, alongside with an upregulation in ATP-binding cassette transporters and the thiol metabolic pathway [193], and crossresistance to miltefosine uptake [194]. Additionally, a large scale proteomic study has identified several proteins that were differentially expressed in amphotericin resistant parasites, including enzymes involved in metabolic pathways (glycolysis, TCA), transcription and translation, ROS scavenging and also heat shock proteins [193, 195].

Miltefosine. One of the biggest efforts in drug discovery against leishmaniasis was to find an efficacious oral drug. Miltefosine (Impavido®, hexadecylphosphocholine) is an alkylphosphocholine that belongs to the structural class of alkylphospholipids, in which the phosphocholine is esterified with a long-chain alcohol [196]. It was initially used as an antineoplastic, but later became the first oral antileishmanial drug to treat visceral leishmaniasis [153]. This drug has also been reported for the treatment of cutaneous leishmaniasis, however two different studies, one from northern Ethiopia and the other from Spain, showed that miltefosine is less effective in HIV co-infected patients [197-201]. The recommended therapy regimen is a single oral dose of $50 \mathrm{mg}$ for patients with less than $25 \mathrm{~kg}$ body weight or a twice daily dose of $50 \mathrm{mg}$ over a period of 28 days for patients weighing more than $25 \mathrm{~kg}$ [185]. This drug is highly effective with mild and temporary toxicity that includes gastrointestinal, hepatic, and renal side effects. Additionally, miltefosine is teratogenic therefore strictly forbidden in pregnant women [156, 200, 202, 203].

Miltefosine induces the parasite's killing through an apoptosis-like process that involves mitochondria membrane depolarization due the inhibition of cytochrome C oxidase [204-207]. This drug also alters the biosynthesis of lipids, through perturbing alkyl-lipid metabolism, glycosylphosphatidylinositol anchor biosynthesis [208], and ether-lipid remodeling through the

INSTITUTO DE INVESTİGAÇÃO E INOVAÇÃO EM SAÚDE UNIVERSIDADE DO PORTO

Rua Alfredo Allen, 208 4200-135 Porto Portugal +351220408800 info@i3s.up.pt www.i3s.up.pt 
inhibition of the alkyl-lyso-phosphatidylcholine specific acyl coenzyme A acyltransferase [209]. Overall, it seems that the intracellular accumulation of the drug, which is mediated by two transporters, is detrimental for its microbicidal action [205]. Miltefosine is prone for resistance emergence: 1) the treatment may often be unsupervised and lack of compliance can lead to subtherapeutical doses in the patients, 2) long half-life, as it can still be detected in the blood 5 months after the treatment [197].

Miltefosine resistant parasites are easily generated in the laboratory, and due to the widespread use of miltefosine, the fear of resistance is eminent [210]. However, no human cases had been reported up until recently [211]. Initial studies demonstrated that the resistance phenotype is associated to a decreased accumulation of the drug in the cell due to an increased drug efflux and a decreased of drug uptake [210, 212-214]. Later, Clos et al. have isolated a gene from $L$. infantum that, upon over-expression, confers protection not only against miltefosine, but also against trivalent antimony [215]. In a recent study, a transcriptomic analysis of resistant versus susceptible strains to miltefosine revealed differential expression of genes related to DNA repair/replication machinery, protein translation and folding, lipid metabolism, antioxidant defense and transporters activity [216]. Miltefosine is certainly the most cost-effective option to treat leishmaniasis in the areas of antimonial resistance, however, its use as first line therapy is inevitably limited by its teratogenicity and high potential for resistance development [175].

Paromomycin. Paromomycin (Aminosidine) is a broad-spectrum aminoglycoside antibiotic belonging to the neomycin family that in 1960s was found to have leishmanicidal activity. It consists of three amino sugars bonded by a glycosidic linkage and a ribofuranosyl subunit in the central position [217]. It was licensed in 2007, in India, as an effective, well tolerated and affordable treatment for visceral leishmaniasis [218]. A 21-day course treatment using an intramuscular injection of $20 \mathrm{mg} / \mathrm{kg}$ of body weight per day can be effectively used $[219,220]$. However, clinical trials in East Africa using $15-\mathrm{mg} / \mathrm{kg}$ regimen for 21 days, showed much lower efficacy, particularly in Sudan where the cure rate was $<50 \%$. Even the increased dose of $20 \mathrm{mg} / \mathrm{kg}$ for 21 days gave only an $85 \%$ cure rate, insufficient for consideration as a monotherapy [221]. In the case of cutaneous leishmaniasis, paromomycin has been formulated for topical treatment of $\mathrm{CL}$, offering the advantage of easier administration, fewer side effects and cost-effectiveness in comparison to systemic treatment [222]. This drug is used in a methylbenzethonium chloride ointment (Leshcutan) as topical treatment [223]. Moreover, in a phase 2, placebo controlled study, carried out in Tunisia and France, the third generation aminoglycoside ointment WR279,396, a hydrophilic formulation of $15 \%$ paromomycin plus $0.5 \%$ gentamicin] was reported to be safe with a cure rate of $94 \%$ [224]. Ototoxicity and local pain upon injection are the main side effects [218] Paramomycin binds to the $30 \mathrm{~S}$ ribosomal subunit and interferes with the initiation of protein synthesis. Paromomycin also interferes with mitochondrial membrane potential, inhibiting respiration and appears to affect plasma membrane fluidity and permeability [225]. No clinical resistance has been reported in the field, however aminoglycosides do have strong potential for resistance development, and it has been induced in vitro [226-228]. In the latter, a decrease in the uptake, coupled with drug efflux have been implicated [228, 229]. Once this drug is inexpensive it has been accepted as a first-line alternative drug in the setting of resistance to classical antileishmanial drugs. Moreover, the combination of antimonial drugs with paromomycin results in a highly efficacious regimen accompanied by a reduction of the side effects of both drugs [230, 231].

Imidazole derivatives, Allopurinol and Sitimaquine. The first oral compound used against leishmaniasis was ketoconazole, an imidazole derivative that inhibit ergosterol

INSTITUTO DE INVESTIIGAÇÃO E INOVAÇÃO EM SAÚDE UNIVERSIDADE DO PORTO 
biosynthesis. This compound, as well as itraconazole and fluconazole, which are also imidazole derivatives, present variable success rates against different causative species of $\mathrm{CL}$ and in general are not very promising as monotherapies against VL $[232,233]$. They may have some interest in the context of a combination therapy against VL [234].

Allopurinol, a hypoxanthine analogue and xanthine oxidase (XO) inhibitor, inhibits purine anabolism in Leishmania [235]. Similarly to the imidazole derivatives, it is not valuable as a monotherapy, but in combination it displays some success in CL but not as promising in VL $[236,237]$.

Sitamaquine (8-aminoquinoline) was specifically developed for VL treatment, actually in $\mathrm{CL}$ the results were disappointing. In high concentrations it affects parasite motility, morphology and growth, however, its mechanism of action is unclear. It seems to be inserted in biological membranes through electrostatic interactions and accumulates in acidocalcisomes [238]. More studies are still required to further understand its mode of action, adverse side-effects and resistance-associated mechanisms, so it can be properly assessed as reasonable alternative to the already established VL treatments [239].

\section{THE PENTOSE PHOSPHATE PATHWAY OF TRYPANOSOMATIDS: DRUG TARGET CANDIDATES}

As mentioned in the previous section, there is still an urgent need for novel drugs against trypanosomatids. A common aim in drug discovery is to find proteins that are essential for parasite survival and/or infectivity and absent or sufficiently different at a structural level from the host [240]. This sections addresses the efforts that have been made to explore the particularities of the pentose phosphate pathway of trypanosomatids and to identify and validate potential drug targets allowing subsequent identification of lead compounds (Table 1). Trypanosomatids have unique organelles in order to respond to the needs inherent to their specific lifestyle within their host. Among those are glycosomes, peroxisome related organelles, which contain enzymes of important metabolic pathways such as glycolysis, pentose phosphate pathway, fatty acid $\beta$-oxidation, gluconeogenesis, purine salvage and biosynthesis of pyrimidines, ether lipids biosynthesis and early parts of the mevalonate pathway [241]. The compartmentalization of different pathways in the glycosomes is an enigma, but in general is thought to prevent the accumulation of toxic intermediates as well as enable a fast metabolic adaptation to environmental changes [241, 242]. Apart from glycolysis, glucose is metabolized by the PPP (Fig. 1), whose role in protozoa and their interaction with their hosts has recently become a very attractive and viable drug target. It is a key metabolic pathway that relies upon glucose and is classically divided in two branches: an oxidative branch and a non-oxidative branch. Some of the resulting products and intermediates (ribose-5-phosphate - R5P, glyceraldehyde-3-phosphate - G3P, fructose-6phosphate - F6P) and cofactors (NADPH) are used to synthesize nucleic acids and lipids, as well as to maintain redox homeostasis [243]. PPP does not necessarily act as a cycle, as the enzymatic reactions can be adjusted according to the cells demands [243]. In most organisms, this pathway localises to the cytosol, but in trypanosomatids it localises between the glycosomes and the cytosol [5]. The oxidative branch is considered unidirectional, and comprises of three enzymatic steps glucose-6-phosphate dehydrogenase (G6PDH), 6phosphogluconolactonase (6PGL), and 6-phosphogluconate dehydrogenase (6PGDH) (Fig 1), for the synthesis of ribulose 5-phosphate (Ru5P), with the concomitant production of two moles of NADPH per mole of glucose 6-phosphate (G6P) consumed [244]. Until now the oxidative branch was subjected to a higher number of studies compared to the non-oxidative 
PPP, however the latter deserves further investigation, since it supplies the parasites with ribose-5-phosphate (R5P), required to produce RNA and DNA, and erythrose 4-phosphate (E4P), a precursor of aromatic amino acids and vitamin B6 [245]. In the bidirectional nonoxidative branch, the Ru5P from the oxidative branch, can be converted into either R5P or xylulose 5-phosphate (X5P). Thereafter two enzymes, transketolase (TKT) and transaldolase $(T A L)$, are responsible for the relative complex interconversion reactions between R5P/X5P and the glycolytic intermediates glyceraldehyde 3-phosphate/fructose 6-phosphate via reshuffling of monophosphate sugars (Fig 1). Through the sharing of these intermediates, TKT and TAL act as a interface between glycolysis and the PPP, allowing rapid interconversion of these important metabolites depending upon the cells requirements [245].

\section{Oxidative branch.}

Glucose-6-phosphate dehydrogenase. Glucose-6-phosphate dehydrogenase (G6PDH; Fig. 1) is the first enzyme of the oxidative branch of PPP, catalysing the oxidation of G6P to 6-phosphogluconolactone (6PGL) as NADP+ is reduced to NADPH (reviewed in [246]). This enzyme shares approximately $50 \%$ identity to its human homologue [247]. It localises mostly to the cytosol, although there is a small fraction compartimentalized in the glycosomes, although a typical peroxisomal targeting sequence (PTS) is absent [248, 249]. T. brucei and $L$. mexicana have a single copy sequence, whereas $T$. cruzi has five copies, two of them being pseudogenes. The crystal structure of the TcG6PDH revealing the molecular basis of substrate and cofactor recognition was recently obtained showing that differences in the cofactor binding site compared to the human homologue allowing future exploration towards the design of new competitive NADP+ inhibitors [250].

This enzyme has been genetically validated as a drug target in $T$. brucei, using RNAi, probably due to the depletion of nucleotide and NADPH pools [251]. Moreover, a critical role in anti-oxidant defence has been demonstrated for G6PDH in both T. cruzi and Leishmania $[252,253]$.

Phosphogluconolactonase. The second step of this pathway is catalysed by 6 phosphogluconolactonase (6PGL; Fig. 1), which hydrolyses 6-phospogluconolactone (6PGL) into 6-phosphogluconate (6PG) [248]. In T. brucei, it localises mostly in the cytosol, but around $15 \%$ localises to the glycosomes, and a PTS-1 signal peptide can be found [249, 254]. It has only $20 \%$ identity to the human homologue and its crystal structure has been solved. Although its substrate, 6-phospogluconolactone, can spontaneously hydrolyse, in conditions of high NADPH demand, it may accumulate especially inside the glycosomes. Due to its electrophilic character, it may irreversibly inactivate key metabolic enzymes. Therefore, 6PGL may have a detrimental role to prevent the accumulation of this PPP intermediate. However, its essentiality has not been addressed in any trypanosomatid [247].

Phosphogluconate dehydrogenase. The last step is catalysed by 6 phosphogluconate dehydrogenase (6PGDH; Fig. 1), which is responsible for the oxidation and decarboxylation of 6 -phosphogluconate $(6 \mathrm{PG})$ to Ru5P, while again reducing NADP+ to $\mathrm{NADPH}$ [255]. It has only around $35 \%$ homology to the human counterpart, however there is a high conservation of the residues involved in the substrate and coenzyme binding, challenging the design of selective inhibitors $[247,256]$. Similarly to the first two enzymes of the pathway, it localises predominantly to the cytosol, and to a less extent to the glycosomes [257]. In $T$. brucei, deletion of 6PGDH leads to the accumulation of 6-phosphogluconate, which inhibits phosphoglucose isomerase and consequently glycolysis. This is probably exacerbated in vivo with the increase of G6P flow through the PPP. Moreover, it remains to be investigated 
whether a decrease in R5P production also plays a role in the observed defect [247]. 6PGDH essentiality has not yet been addressed in Leishmania and T. cruzi.

In summary, the oxidative branch is therefore of critical importance to these parasites, as it supplies not only Ru5P, a precursor of the non-oxidative branch, but also NADPH, an essential molecule for lipid synthesis, defence against oxidative stress by regenerating GSH, among other important cellular processes [247].

Non-oxidative branch.

Ribose 5-phosphate isomerase. Ribose-5-phosphate isomerase (RPI; Fig. 1) is responsible for the interconversion of R5P in Ru5P. There are two types of RPI enzymes, type A RPI (RPIA) is represented in all life kingdoms, contrasting with the type $B$ (RPIB), restricted to some bacteria and protozoans [258]. An adverse phenotype was observed in E. coli [258] and also humans [259] upon RPI deficiency, suggesting a critical conserved role through evolution. Trypanosomatids possess a type B RPI, which is absent from humans that instead have a structurally unrelated type A and therefore possibly an ideal drug target [260-265]. Recombinant enzymes from L. donovani [262], L. infantum [261], L. major [261], T. brucei [263] and T. cruzi $[263,264]$ have been formally demonstrated to have in vitro isomerase activity by catalysing the interconversion of R5P and Ru5P. The Km values for both R5P and Ru5P were similar between Leishmania and trypanosomes enzymes, however, Kcat values are considerably higher for Leishmania, in both direct and inverse reactions [261-264]. A decrease in $\mathrm{Km}$ and an increase in Kcat were consistently observed for Ru5P in comparison to R5P, suggesting that the conversion of Ru5P into R5P is favoured, which might be explained by the important role of R5P as a building block for nucleic acid synthesis.

Regarding RPI localization, LmRPIB possesses a PTS-2 signal sequence (-RVALGCDHA-), which is conserved in $L$. infantum and $L$. donovani [249]. However, recent proteomic analysis of $L$. donovani glycosomes failed to detect RPIB in these organelles [266]. The same analysis detected HGPRT (PTS-1), aldolase (PTS-2), as well as some enzymes of PPP that are upstream RPIB, namely putative G6PD (PTS-1), putative 6PGDH (non-identified), or enzymes downstream RPIB, such as TKL (PTS-1), putative RPE (PTS-1) and putative TAL (nonidentified signal peptide), or other related proteins like putative ribokinase (PTS-2 signal peptide). In both $T$. brucei and $L$. infantum RPIB shows a dual localization despite preferentially located in the cytosol compared to the glycosomes [261, 263]. The amount of $\mathrm{RPBI}$ that is in the cytosol or the glycosomes, as well as whether the distribution changes throughout the parasite life cycle needs further investigation.

In $T$. brucei, RNAi induction against RPIB led to a significant decrease of bloodstream forms proliferation in vitro but more importantly it dramatically affects the infectivity of the parasites leading to a decrease in parasitaemia and a prolonged mice survival [261]. Phenotypic reversion was achieved by complementing induced RNAi clones with an ectopic copy of the $T$. cruzi gene suggesting ultimately a conserved role of RPIB among different Trypanosoma species. Moreover, RPIB is as an essential gene as $T$. brucei is resistant to complete RPIB gene removal and mice infected with single knockout mutants showed prolonged survival upon infection [261]. RPIB gene essentiality for parasites survival was also demonstrated in $L$. infantum as null mutants generation was only possible when an episomal copy of RPIB gene was introduced and the latter was retained both in vitro and in vivo in the absence of drug pressure [261]. Importantly, the inability to remove the second allele of RPIB gene in sKO mutants complemented with an episomal copy of RPIB carrying a mutation that abolishes isomerase activity suggests the essentiality is due to its metabolic function [261]. This is 
particularly important from a drug discovery point of view, as several enzymes have been reported to exhibit protein moonlighting in trypanosomatids [267-269]. Indeed, many enzymes have the ability to perform multiple, sometimes unrelated, functions and to be involved in different multiprotein complexes or biochemical pathways therefore being characterized as moonlighting proteins [270]. Studies on Leishmania infantum mitochondrial peroxiredoxin clearly mirror this issue. Unexpectedly, the moonlighting chaperone function is critical for parasite virulence, but not its peroxidase activity [267, 268]. In this sense, from a drug discovery perspective, it is critical to assess if the expected metabolic function is one that is detrimental to parasite survival and/or infectivity and therefore the one to be targeted by inhibitory molecules.

Ribulose 5-phosphate epimerase. Another player in the PPP non-oxidative branch is ribulose-5-phosphate epimerase (RPE; Fig. 1), which interconverts Ru5P and X5P. In $T$. brucei RPE activity was detected in procyclics, but not in parasites isolated from mice [260]. Leishmania and T. cruzi encode for two isoenzymes that differ in the presence and absence of a PTS [271, 272], and the first has recently been detected in L. donovani glycosomes [266]. Additionaly, its activity has been detected in L. mexicana promastigotes and was 3 fold higher than its competitor enzyme, RPIB [273]. In T. cruzi despite the high sequence similarity between the two isoenzymes the cytosolic TcRPE1 shows a specific activity 80-100-fold greater than the glycosomal isoenzyme TcRPE2 [271]. Furthermore, the subcellular localization of TCRPE2 is absolutely dependent on the presence of its targeting signal, since over-expression of a truncated mutant lacking the putative glycosomal targeting signal, not only remains in the cytosol, but also negatively affects parasite growth, extending its doubling time in vitro [271].

RPE has not been subjected to a targeted study in any trypanosomatid to address whether it is essential for survival. However, considering that the genome-wide RNAi screening in $T$. brucei using RITseq indicated that mRNA depletion did not cause any fitness cost, and that its activity had not been detected in parasites recovered from the mice (Alsford et al, 2011; Cronin et al, 1989; Kovárová et al, 2016), this indicates that RPE may not qualify as a drug target in T. brucei. In Leishmania and T. cruzi, this may be different and requires further research.

Transketolase. Transketolase (TKT; Fig. 1) is an enzyme capable of catalysing two distinct reversible reactions that involvs the transfer of a two carbon unit: (i) from xylulose 5phosphate (X5P) to R5P, producing glyceraldehyde 3-phosphate (G3P) and sedoheptulose 7phosphate (S7P), and (ii) from xylulose 5-phosphate (X5P) to erythrose 4-phosphate (E4P) to generate glyceraldehyde 3-phosphate (G3P) and fructose 6-phosphate (F6P), using thiamine diphosphate as a cofactor [274]. This enzyme may prevent the accumulation of toxic metabolites or modulate NADPH production by redirecting sugar phosphates towards the oxidative branch of the pathway [247]. In trypanosomatids, at least two residues involved in the substrate and cofactor binding are not conserved when comparing to the human counterpart [247]. TKT is expressed in all developmental stages of $T$. cruzi and its activity has been reported in several Leishmania species [247]. In particular, in L. mexicana it displays dual localization, in cytosol and glycosomes [275]. TKT activity has not been detected in $T$. brucei parasites recovered from the mice [260], very similarly to RPE. Apparently a great extent of the non-oxidative branch of PPP appears dispensable for $T$. brucei bloodstream forms contrarily to insect stage [247, 276]. This metabolic adaptation may be employed in order to channel sugar metabolization exclusively into R5P and NADPH generation, to support the high proliferation rate of the bloodstream forms [247, 276]. Since T. cruzi and Leishmania present a fully operative PPP, the role of TKT in these parasites still awaits to be unravelled.

INSTITUTO DE INVESTİGAÇÃO E INOVAÇÃO EM SAÚDE UNIVERSIDADE DO PORTO

Rua Alfredo Allen, 208 4200-135 Porto Portugal +351220408800 info@i3s.up.pt www.i3s.up.pt 
TKT is expressed in all developmental stages of $T$. cruzi and its activity has been reported in several Leishmania species [247]. In particular, in L. mexicana it displays dual localization (cytosol and glycosomes) [275]. Since T. cruzi and Leishmania present a fully operative PPP, the role of TKT in these parasites still awaits further investigation.

Transaldolase. Transaldolase (TAL, Fig. 1) catalyses the reversible transfer a threecarbon fragment, dihydroaxyacetone, from sedoheptulose 7-phosphate (S7P) to glyceraldehyde 3-phosphate (G3P), producing fructose 6-phosphate (F6P) and erythrose 4phosphate (E4P) [247].

A gene annotated as TAL was cloned from $T$. brucei and the expressed protein was shown to be capable to form O8P using R5P and F6P as acceptor and donor substrates, respectively [276]. This indicates TAL as a likely source of the higher carbon content carbohydrates referred to earlier [243]. TAL activity has been detected in Leishmania [247] and further studies need to be undertaken to better understand its role in both Leishmania and T. cruzi.

It is also noteworthy that organisms, like yeast, have an alternative NADP-independent pathway for R5P synthesis, designated riboneogenesis. This pathway transforms glycolytic intermediates into sedoheptulose-1,7-biphosphate, by a combined action of the TKL and an aldolase (ALD). Subsequently, sedoheptulose-1,7-biphosphate, through the action of a sedoheptulose-1,7-biphosphatase (SBP), is converted into S7P, which can in turn be a substrate of TKL to ultimately generate R5P [277]. Genes encoding a putative sedoheptulose1, 7-biphosphatase (SBP) are present in the genomes of both T. brucei and T. cruzi, but absent in Leishmania [272]. Importantly, it has not been formally demonstrated that this pathway operates in trypanosomes.

Overall the components of the non-oxidative branch of PPP are more heterogeneous, comprising members that do not possess a mammalian homologue (RPIB) and others that are developmentally regulated and specifies-specific dispensable (RPE and TKT) [247].

\section{INTERFERING WITH PPP: DO TRYPANOSOMATIDS COPE OR NOT?}

The oxidative branch of PPP is of great importance to Leishmania and trypanosomes, as it supplies NADPH, an essential molecule for lipid synthesis and anti-oxidant defence, among other important cellular processes [247]. Therefore, it is easy to imagine that once inhibiting an enzyme from the oxidative branch, the depletion of the NADPH pool will be critical for these parasites, as observed when knocking down G6PDH [251]. In the case of 6PGDH, which catalyses the third step of PPP, its deletion also leads to the accumulation of 6phosphogluconate, which inhibits phosphoglucose isomerase and consequently glycolysis. Moreover, the subsequent depletion in R5P production may also play a role [247].

We have demonstrated that RPIB isomerase is essential for $T$. brucei and L. infantum [261] and therefore, it would be worth exploring the metabolic implications of its inactivation/inhibition. At this point, we can only speculate why an enzyme involved in the nonoxidative branch of the PPP, in which interconversion reactions take place, is essential. In Leishmania, our in vitro data suggest that RPIB is critical for the development of intracellular amastigotes [261]. These forms have nutritional requirements that are more complex than those of the majority of prokaryotes and fungal pathogens. Specifically, Leishmania is one of the very few pathogens that infect macrophages and does not escape or subvert the 
endocytic pathway, oddly dwelling in a mature phagolysosome [278]. This compartment may appear very hostile! However, it may be a permissive niche regarding nutrient availability. Yet, to benefit from this large nutrient supply, pathogens must employ mechanisms to counteract the host cell microbicidal machinery, and Leishmania has successfully mastered it [279].

A very dramatic modification in amastigotes concerns the global downregulation of nutrient transporters as a stringent metabolic response is activated [280]. The consequent overall decrease in nutrient uptake in amastigotes as they enter this metabolic stringency may render the parasites more dependent on RPIB for R5P synthesis. However, there are alternatives sources for R5P production that bypass RPIB. Some organisms, like yeast, have an alternative NADP-independent pathway for R5P synthesis which relies on the combined action of sedoheptulose-1,7-biphosphate (SBP), TKL and aldolase. Leishmania in opposition to trypanosomes lacks SBP sequence and T. brucei does not express TKL in bloodstream forms: could this render them more dependent on RPIB? It would be very interesting to investigate it in $T$. cruzi, as it encodes the putative SBP and expresses TKL in all developmental stages $[247,272,276]$.

Another possibility is that the absence/inhibition of RPIB may lead to the accumulation of Ru5P, which may modulate the activity of the upstream PPP enzymes by negative feedback. This sort of regulation is absent in several key enzymes of central carbon metabolism in trypanosomatids [281-283], thus it is unlikely to operate.

Moreover, a study has demonstrated that human RPIA modulates hepatocarcinogenesis [284], and its knockdown leads to Ru5P accumulation, which is further converted into X5P by RPE. It has been reported that X5P can activate PP2A [285], which negatively regulates ERK signalling for cell proliferation. Whether this sort of regulation takes place in trypanosomatids is unknown. However, they encode for a RPE [266, 273, 286], PP2A [287] and MAP kinases [288]. This would be particularly interesting to investigate in Leishmania and T. cruzi, as RPE is not expressed in the mammalian stage of $T$. brucei.

These different parasites undergo several developmental stages in different hosts, experiencing environmental conditions that are dramatically different during their life cycle. Therefore, when looking at different parasites or different forms of the same parasite, it is not surprising that their metabolism also shifts and adapts, and if many similar traits can be found, certainly many particularities as well. A better understanding of their metabolic pathways and their nutritional needs is critical to enlighten us on how to exploit them as new venues towards novel antimicrobial strategies.

\section{DEVELOPING TRYPANOCIDAL SPECIFIC INHIBITORS OF THE PPP}

Inhibitors against the trypanosomatids G6PDH and 6PGDH from the oxidative branch and RPIB from the non-oxidative branch have been described (Fig. 2). Indeed, the steroids dehydroepiandrosterone (DHEA) and epiandrosterone (EA) (Fig. 2A) were shown to inhibit the TbG6PDH in an uncompetitive fashion with $K i$ values about 6-fold lower than those reported for the human enzyme and exhibit in vitro anti-parasitic activity against bloodstream forms $T$. brucei [251]. However, DHEA failed to decrease T. cruzi in vitro growth, but its brominated derivatives, which are more potent inhibitors, displayed $\mathrm{EC}_{50}$ values in the low-mid micromolar range, similarly to benznidazole [289-291]. Interestingly, DHEA and EA did not inhibit $L$. 
mexicana G6PDH and had no impact on parasite in vitro growth rate of cultured promastigote parasites, meaning that the effect mediated by these drugs is specific to trypanosomes [253].

Some analogues/mimics of the high-energy intermediates (hydroxamate derivatives of Derythronic acid, Fig. 2B) were found to be potent and selective inhibitors of Tb6PGDH [292], however, the best compounds showed no trypanocidal activity due to their poor membrane permeability. Therefore, phosphate prodrugs were developed to overcome this limitation, in particular, aryl phosphoramidate prodrugs of 2,3-O-isopropylidene-4-erythrono hydroxamate (Fig. 2B) displayed both potent activity against Tb6PGDH and in vitro anti-parasitic activity [293, 294].

The analogous inhibitor of the isomerization intermediate, 4-phospho-D-erythronohydroxamic acid (4-PEH, Fig. 2C), was shown to be a good competitive inhibitor against RPIBs [264, 295], however it also strongly inhibits class A RPI enzyme found in humans [295]. 4-PEH was also shown to inhibit the TbRPIB, LIRPIB and LmRPIB, but only in the millimolar range [296], thus unlikely to show any potent anti-parasitic in vitro or in vivo activity.

Other possible future sources of parasite selective inhibitors may be those that are identified for similar enzymes activities in the glycolytic pathway, which bind similar substrates and have similar enzyme functions, such as phosphoglucose isomerase, fructose-bisphosphate aldolases and the triosephosphate isomerase. Thus, an inhibitor against these glycolytic enzymes could also be targeting enzymes of the PPP, which could be of added benefit.

\section{CONCLUDING REMARKS}

The PPP of trypanosomatids have attractive drug target candidates due to their essential role for parasites survival and/or infectivity, but also due to the lack or low homology with their human counterparts. Unfortunately, the target-based approach for drug discovery has not been as successful as initially expected over the past 10-15 years for several reasons. These usually concern poor membrane permeability or metabolic inactivation of the enzymatic inhibitors when tested against the whole parasites and or in animal model due to fast clearance. Others may include: 1) the enzyme may be abundantly expressed and/or present a fast turnover; 2) the compound can have higher affinity for other targets (off-target) that are present in the host and/or dispensable for the parasite; 3 ) in the case of Leishmania, the ability for stochastic DNA amplification may allow a higher expression of the molecular target; 4) protein moonlighting, in which the atypical function is the one detrimental for parasite survival. In the case of the mammalian stage of Leishmania, a drug has to cross the host cell, the phagolysosome and the parasite membranes, and if the enzyme is inside an organelle, another membrane has to be crossed. The fact that some of the targets of the PPP present dual localization, as they localize mainly to the cytosol, but also in part to the glycosomes raises particular concerns in terms of redundancy and/or accessibility. Indeed, it would be important to address whether the localization in the glycosomes is essential for the parasite, as its activity inside the organelle may be harder to target. Another critical issue awaiting further investigation is the enzymes druggability, what happens when the enzyme is inhibited and the substrate concentration increases, a competitive inhibitor would simply be outcompeted by the higher substrate concentration, alleviating the blockage and thus allowing the parasite to survive and possibly evolve resistance.

\section{ACKNOWLEDGEMENTS}


This article is a result of the projects NORTE-01-0145-FEDER-000012, supported by Norte Portugal Regional Operational Programme (NORTE 2020), under the PORTUGAL 2020 Partnership Agreement, through the European Regional Development Fund (ERDF) and from the European Community's Seventh Framework Programme under grant agreements No. 602773 (Project KINDRED). JT is an Investigator FCT funded by National funds through FCT and co-funded through European Social Fund within the Human Potential Operating Programme.

\section{REFERENCES}

[1] Simpson, A.G.; Stevens, J.R.; Lukes, J., The evolution and diversity of kinetoplastid flagellates. Trends in parasitology, 2006, 22, (4), 168-174.

[2] Podlipaev, S., The more insect trypanosomatids under study-the more diverse Trypanosomatidae appears. International journal for parasitology, 2001, 31, (5-6), 648-652.

[3] Beverley, S.M., Hijacking the cell: parasites in the driver's seat. Cell, 1996, 87, (5), 787-789.

[4] Campbell, D.A.; Thomas, S.; Sturm, N.R., Transcription in kinetoplastid protozoa: why be normal? Microbes and infection / Institut Pasteur, 2003, 5, (13), 1231-1240.

[5] Hannaert, V.; Bringaud, F.; Opperdoes, F.R.; Michels, P.A., Evolution of energy metabolism and its compartmentation in Kinetoplastida. Kinetoplastid Biol Dis, 2003, 2, (1), 11.

[6] Simpson, L.; Aphasizhev, R.; Gao, G.; Kang, X., Mitochondrial proteins and complexes in Leishmania and Trypanosoma involved in $\mathrm{U}$-insertion/deletion RNA editing. Rna, 2004, 10, (2), 159-170.

[7] Lukes, J.; Hashimi, H.; Zikova, A., Unexplained complexity of the mitochondrial genome and transcriptome in kinetoplastid flagellates. Current genetics, 2005, 48, (5), 277299.

[8] Liu, B.; Liu, Y.; Motyka, S.A.; Agbo, E.E.; Englund, P.T., Fellowship of the rings: the replication of kinetoplast DNA. Trends Parasitol, 2005, 21, (8), 363-369.

[9] Krauth-Siegel, R.L.; Comini, M.A., Redox control in trypanosomatids, parasitic protozoa with trypanothione-based thiol metabolism. Biochimica et biophysica acta, 2008, 1780, (11), 1236-1248.

[10] Smirlis, D.; Soares, M.B., Selection of molecular targets for drug development against trypanosomatids. Sub-cellular biochemistry, 2014, 74, 43-76.

[11] Barrett, M.P.; Burchmore, R.J.; Stich, A.; Lazzari, J.O.; Frasch, A.C.; Cazzulo, J.J.; Krishna, S., The trypanosomiases. Lancet, 2003, 362, (9394), 1469-1480.

[12] Steverding, D., The history of African trypanosomiasis. Parasites \& vectors, 2008, 1, (1), 3.

[13] Solano, P.; Torr, S.J.; Lehane, M.J., Is vector control needed to eliminate gambiense human African trypanosomiasis? Frontiers in cellular and infection microbiology, 2013, 3, 33. 
[14] Franco, J.R.; Simarro, P.P.; Diarra, A.; Jannin, J.G., Epidemiology of human African trypanosomiasis. Clinical epidemiology, 2014, 6, 257-275.

[15] Berrang-Ford, L.; Berke, O.; Sweeney, S.; Abdelrahman, L., Sleeping sickness in southeastern Uganda: a spatio-temporal analysis of disease risk, 1970-2003. Vector borne and zoonotic diseases, 2010, 10, (10), 977-988.

[16] Lejon, V.; Boelaert, M.; Jannin, J.; Moore, A.; Buscher, P., The challenge of Trypanosoma brucei gambiense sleeping sickness diagnosis outside Africa. The Lancet infectious diseases, 2003, 3, (12), 804-808.

[17] Van Den Abbeele, J.; Caljon, G.; De Ridder, K.; De Baetselier, P.; Coosemans, M., Trypanosoma brucei modifies the tsetse salivary composition, altering the fly feeding behavior that favors parasite transmission. PLoS pathogens, 2010, 6, (6), e1000926.

[18] Vickerman, K., Developmental cycles and biology of pathogenic trypanosomes. British medical bulletin, 1985, 41, (2), 105-114.

[19] Caljon, G.; Van Reet, N.; De Trez, C.; Vermeersch, M.; Perez-Morga, D.; Van Den Abbeele, J., The Dermis as a Delivery Site of Trypanosoma brucei for Tsetse Flies. PLoS Pathog, 2016, 12, (7), e1005744.

[20] Capewell, P.; Cren-Travaille, C.; Marchesi, F.; Johnston, P.; Clucas, C.; Benson, R.A.; Gorman, T.A.; Calvo-Alvarez, E.; Crouzols, A.; Jouvion, G.; Jamonneau, V.; Weir, W.; Stevenson, M.L.; O'Neill, K.; Cooper, A.; Swar, N.K.; Bucheton, B.; Ngoyi, D.M.; Garside, P.; Rotureau, B.; MacLeod, A., The skin is a significant but overlooked anatomical reservoir for vector-borne African trypanosomes. Elife, 2016, 5.

[21] Trindade, S.; Rijo-Ferreira, F.; Carvalho, T.; Pinto-Neves, D.; Guegan, F.; ArestaBranco, F.; Bento, F.; Young, S.A.; Pinto, A.; Van Den Abbeele, J.; Ribeiro, R.M.; Dias, S.; Smith, T.K.; Figueiredo, L.M., Trypanosoma brucei Parasites Occupy and Functionally Adapt to the Adipose Tissue in Mice. Cell Host Microbe, 2016, 19, (6), 837-848.

[22] Mony, B.M.; MacGregor, P.; Ivens, A.; Rojas, F.; Cowton, A.; Young, J.; Horn, D.; Matthews, K., Genome-wide dissection of the quorum sensing signalling pathway in Trypanosoma brucei. Nature, 2014, 505, (7485), 681-685.

[23] Langousis, G.; Hill, K.L., Motility and more: the flagellum of Trypanosoma brucei. Nature reviews. Microbiology, 2014, 12, (7), 505-518.

[24] Rotureau, B.; Subota, I.; Buisson, J.; Bastin, P., A new asymmetric division contributes to the continuous production of infective trypanosomes in the tsetse fly. Development, 2012, 139, (10), 1842-1850.

[25] Van Den Abbeele, J.; Claes, Y.; van Bockstaele, D.; Le Ray, D.; Coosemans, M., Trypanosoma brucei spp. development in the tsetse fly: characterization of the postmesocyclic stages in the foregut and proboscis. Parasitology, 1999, 118 (Pt 5), 469-478.

[26] Urwyler, S.; Studer, E.; Renggli, C.K.; Roditi, I., A family of stage-specific alanine-rich proteins on the surface of epimastigote forms of Trypanosoma brucei. Molecular microbiology, 2007, 63, (1), 218-228.

[27] Malvy, D.; Chappuis, F., Sleeping sickness. Clinical microbiology and infection : the official publication of the European Society of Clinical Microbiology and Infectious Diseases, 2011, 17, (7), 986-995. 
[28] Horn, D., Antigenic variation in African trypanosomes. Molecular and biochemical parasitology, 2014, 195, (2), 123-129.

[29] Bockstal, V.; Guirnalda, P.; Caljon, G.; Goenka, R.; Telfer, J.C.; Frenkel, D.; Radwanska, M.; Magez, S.; Black, S.J., T. brucei infection reduces B lymphopoiesis in bone marrow and truncates compensatory splenic lymphopoiesis through transitional B-cell apoptosis. PLoS pathogens, 2011, 7, (6), e1002089.

[30] Semballa, S.; Geffard, M.; Daulouede, S.; Malvy, D.; Veyret, B.; Lemesre, J.L.; Holzmuller, P.; Mnaimneh, S.; Vincendeau, P., Antibodies directed against nitrosylated neoepitopes in sera of patients with human African trypanosomiasis. Tropical medicine \& international health : $T M \& I H, 2004,9,(10), 1104-1110$.

[31] Jamonneau, V.; Ilboudo, H.; Kabore, J.; Kaba, D.; Koffi, M.; Solano, P.; Garcia, A.; Courtin, D.; Laveissiere, C.; Lingue, K.; Buscher, P.; Bucheton, B., Untreated human infections by Trypanosoma brucei gambiense are not $100 \%$ fatal. PLoS neglected tropical diseases, 2012, 6, (6), e1691.

[32] WHO Trypanosomiasis, human African (sleeping sickness). Fact sheet $N^{\circ} 259$.; World Health Organization: Geneva, 2015.

[33] Barrett, M.P.; Vincent, I.M.; Burchmore, R.J.; Kazibwe, A.J.; Matovu, E., Drug resistance in human African trypanosomiasis. Future Microbiol, 2011, 6, (9), 1037-1047.

[34] Sands, M.; Kron, M.A.; Brown, R.B., Pentamidine: a review. Reviews of infectious diseases, 1985, 7, (5), 625-634.

[35] Carter, N.S.; Berger, B.J.; Fairlamb, A.H., Uptake of diamidine drugs by the P2 nucleoside transporter in melarsen-sensitive and -resistant Trypanosoma brucei brucei. The Journal of biological chemistry, 1995, 270, (47), 28153-28157.

[36] De Koning, H.P., Uptake of pentamidine in Trypanosoma brucei brucei is mediated by three distinct transporters: implications for cross-resistance with arsenicals. Molecular pharmacology, 2001, 59, (3), 586-592.

[37] Alsford, S.; Eckert, S.; Baker, N.; Glover, L.; Sanchez-Flores, A.; Leung, K.F.; Turner, D.J.; Field, M.C.; Berriman, M.; Horn, D., High-throughput decoding of antitrypanosomal drug efficacy and resistance. Nature, 2012, 482, (7384), 232-236.

[38] Moreno, T.; Pous, J.; Subirana, J.A.; Campos, J.L., Coiled-coil conformation of a pentamidine-DNA complex. Acta crystallographica. Section D, Biological crystallography, 2010, 66, (Pt 3), 251-257.

[39] Lanteri, C.A.; Tidwell, R.R.; Meshnick, S.R., The mitochondrion is a site of trypanocidal action of the aromatic diamidine DB75 in bloodstream forms of Trypanosoma brucei. Antimicrobial agents and chemotherapy, 2008, 52, (3), 875-882.

[40] Delespaux, V.; de Koning, H.P., Drugs and drug resistance in African trypanosomiasis. Drug resistance updates : reviews and commentaries in antimicrobial and anticancer chemotherapy, 2007, 10, (1-2), 30-50.

[41] Baker, N.; Glover, L.; Munday, J.C.; Aguinaga Andres, D.; Barrett, M.P.; de Koning, H.P.; Horn, D., Aquaglyceroporin 2 controls susceptibility to melarsoprol and pentamidine in African trypanosomes. Proceedings of the National Academy of Sciences of the United States of America, 2012, 109, (27), 10996-11001. 
[42] Jeacock, L.; Baker, N.; Wiedemar, N.; Maser, P.; Horn, D., Aquaglyceroporin-null trypanosomes display glycerol transport defects and respiratory-inhibitor sensitivity. PLoS Pathog, 2017, 13, (3), e1006307.

[43] Barrett, M.P.; Boykin, D.W.; Brun, R.; Tidwell, R.R., Human African trypanosomiasis: pharmacological re-engagement with a neglected disease. British journal of pharmacology, 2007, 152, (8), 1155-1171.

[44] Kennedy, P.G., Clinical features, diagnosis, and treatment of human African trypanosomiasis (sleeping sickness). The Lancet. Neurology, 2013, 12, (2), 186-194.

[45] Vansterkenburg, E.L.; Coppens, I.; Wilting, J.; Bos, O.J.; Fischer, M.J.; Janssen, L.H.; Opperdoes, F.R., The uptake of the trypanocidal drug suramin in combination with lowdensity lipoproteins by Trypanosoma brucei and its possible mode of action. Acta tropica, 1993, 54, (3-4), 237-250.

[46] Alsford, S.; Field, M.C.; Horn, D., Receptor-mediated endocytosis for drug delivery in African trypanosomes: fulfilling Paul Ehrlich's vision of chemotherapy. Trends in parasitology, 2013, 29, (5), 207-212.

[47] Wang, C.C., Molecular mechanisms and therapeutic approaches to the treatment of African trypanosomiasis. Annual review of pharmacology and toxicology, 1995, 35, 93-127.

[48] Morgan, H.P.; McNae, I.W.; Nowicki, M.W.; Zhong, W.; Michels, P.A.; Auld, D.S.; Fothergill-Gilmore, L.A.; Walkinshaw, M.D., The trypanocidal drug suramin and other trypan blue mimetics are inhibitors of pyruvate kinases and bind to the adenosine site. J Biol Chem, 2011, 286, (36), 31232-31240.

[49] Zoltner, M.; Leung, K.F.; Alsford, S.; Horn, D.; Field, M.C., Modulation of the Surface Proteome through Multiple Ubiquitylation Pathways in African Trypanosomes. PLoS Pathog, 2015, 11, (10), e1005236.

[50] Friedheim, E.A., Mel B in the treatment of human trypanosomiasis. The American journal of tropical medicine and hygiene, 1949, 29, (2), 173-180.

[51] Schmid, C.; Richer, M.; Bilenge, C.M.; Josenando, T.; Chappuis, F.; Manthelot, C.R.; Nangouma, A.; Doua, F.; Asumu, P.N.; Simarro, P.P.; Burri, C., Effectiveness of a 10-day melarsoprol schedule for the treatment of late-stage human African trypanosomiasis: confirmation from a multinational study (IMPAMEL II). The Journal of infectious diseases, 2005, 191, (11), 1922-1931.

[52] Blum, J.; Nkunku, S.; Burri, C., Clinical description of encephalopathic syndromes and risk factors for their occurrence and outcome during melarsoprol treatment of human African trypanosomiasis. Tropical medicine \& international health : TM \& IH, 2001, 6, (5), 390400.

[53] Brun, R.; Blum, J.; Chappuis, F.; Burri, C., Human African trypanosomiasis. Lancet, 2010, 375, (9709), 148-159.

[54] Meshnick, S.R.; Blobstein, S.H.; Grady, R.W.; Cerami, A., An approach to the development of new drugs for African trypanosomiasis. The Journal of experimental medicine, 1978, 148, (2), 569-579.

[55] Carter, N.S.; Fairlamb, A.H., Arsenical-resistant trypanosomes lack an unusual adenosine transporter. Nature, 1993, 361, (6408), 173-176. 
[56] Fairlamb, A.H.; Henderson, G.B.; Cerami, A., Trypanothione is the primary target for arsenical drugs against African trypanosomes. Proceedings of the National Academy of Sciences of the United States of America, 1989, 86, (8), 2607-2611.

[57] Fairlamb, A.H., Chemotherapy of human African trypanosomiasis: current and future prospects. Trends in parasitology, 2003, 19, (11), 488-494.

[58] Fairlamb, A.H.; Smith, K.; Hunter, K.J., The interaction of arsenical drugs with dihydrolipoamide and dihydrolipoamide dehydrogenase from arsenical resistant and sensitive strains of Trypanosoma brucei brucei. Molecular and biochemical parasitology, 1992, 53, (12), 223-231.

[59] Van Schaftingen, E.; Opperdoes, F.R.; Hers, H.G., Effects of various metabolic conditions and of the trivalent arsenical melarsen oxide on the intracellular levels of fructose 2,6-bisphosphate and of glycolytic intermediates in Trypanosoma brucei. European journal of biochemistry / FEBS, 1987, 166, (3), 653-661.

[60] Legros, D.; Evans, S.; Maiso, F.; Enyaru, J.C.; Mbulamberi, D., Risk factors for treatment failure after melarsoprol for Trypanosoma brucei gambiense trypanosomiasis in Uganda. Trans R Soc Trop Med Hyg, 1999, 93, (4), 439-442.

[61] Brun, R.; Schumacher, R.; Schmid, C.; Kunz, C.; Burri, C., The phenomenon of treatment failures in Human African Trypanosomiasis. Tropical medicine \& international health : $T M \& I H, 2001,6,(11), 906-914$.

[62] Stanghellini, A.; Josenando, T., The situation of sleeping sickness in Angola: a calamity. Tropical medicine \& international health : $T M \& I H, 2001,6,(5), 330-334$.

[63] Maser, P.; Sutterlin, C.; Kralli, A.; Kaminsky, R., A nucleoside transporter from Trypanosoma brucei involved in drug resistance. Science, 1999, 285, (5425), 242-244.

[64] Stewart, M.L.; Burchmore, R.J.; Clucas, C.; Hertz-Fowler, C.; Brooks, K.; Tait, A.; Macleod, A.; Turner, C.M.; De Koning, H.P.; Wong, P.E.; Barrett, M.P., Multiple genetic mechanisms lead to loss of functional TbAT1 expression in drug-resistant trypanosomes. Eukaryotic cell, 2010, 9, (2), 336-343.

[65] Bridges, D.J.; Gould, M.K.; Nerima, B.; Maser, P.; Burchmore, R.J.; de Koning, H.P., Loss of the high-affinity pentamidine transporter is responsible for high levels of crossresistance between arsenical and diamidine drugs in African trypanosomes. Molecular pharmacology, 2007, 71, (4), 1098-1108.

[66] Nerima, B.; Matovu, E.; Lubega, G.W.; Enyaru, J.C., Detection of mutant P2 adenosine transporter (TbAT1) gene in Trypanosoma brucei gambiense isolates from northwest Uganda using allele-specific polymerase chain reaction. Tropical medicine \& international health : $T M \& I H, 2007,12,(11), 1361-1368$.

[67] Kazibwe, A.J.; Nerima, B.; de Koning, H.P.; Maser, P.; Barrett, M.P.; Matovu, E., Genotypic status of the TbAT1/P2 adenosine transporter of Trypanosoma brucei gambiense isolates from Northwestern Uganda following melarsoprol withdrawal. PLoS neglected tropical diseases, 2009, 3, (9), e523.

[68] Matovu, E.; Geiser, F.; Schneider, V.; Maser, P.; Enyaru, J.C.; Kaminsky, R.; Gallati, S.; Seebeck, T., Genetic variants of the TbAT1 adenosine transporter from African trypanosomes in relapse infections following melarsoprol therapy. Molecular and biochemical parasitology, 2001, 117, (1), 73-81. 
[69] Geiser, F.; Luscher, A.; de Koning, H.P.; Seebeck, T.; Maser, P., Molecular pharmacology of adenosine transport in Trypanosoma brucei: P1/P2 revisited. Molecular pharmacology, 2005, 68, (3), 589-595.

[70] Matovu, E.; Stewart, M.L.; Geiser, F.; Brun, R.; Maser, P.; Wallace, L.J.; Burchmore, R.J.; Enyaru, J.C.; Barrett, M.P.; Kaminsky, R.; Seebeck, T.; de Koning, H.P., Mechanisms of arsenical and diamidine uptake and resistance in Trypanosoma brucei. Eukaryotic cell, 2003, 2, (5), 1003-1008.

[71] Janne, J.; Alhonen-Hongisto, L.; Seppanen, P.; Siimes, M., Use of polyamine antimetabolites in experimental tumours and in human leukemia. Medical biology, 1981, 59, (5-6), 448-457.

[72] Chappuis, F.; Udayraj, N.; Stietenroth, K.; Meussen, A.; Bovier, P.A., Eflornithine is safer than melarsoprol for the treatment of second-stage Trypanosoma brucei gambiense human African trypanosomiasis. Clinical infectious diseases : an official publication of the Infectious Diseases Society of America, 2005, 41, (5), 748-751.

[73] Balasegaram, M.; Harris, S.; Checchi, F.; Ghorashian, S.; Hamel, C.; Karunakara, U., Melarsoprol versus eflornithine for treating late-stage Gambian trypanosomiasis in the Republic of the Congo. Bulletin of the World Health Organization, 2006, 84, (10), 783-791.

[74] Priotto, G.; Pinoges, L.; Fursa, I.B.; Burke, B.; Nicolay, N.; Grillet, G.; Hewison, C.; Balasegaram, M., Safety and effectiveness of first line eflornithine for Trypanosoma brucei gambiense sleeping sickness in Sudan: cohort study. Bmj, 2008, 336, (7646), 705-708.

[75] Burri, C.; Brun, R., Eflornithine for the treatment of human African trypanosomiasis. Parasitology research, 2003, 90 Supp 1, S49-52.

[76] Poulin, R.; Lu, L.; Ackermann, B.; Bey, P.; Pegg, A.E., Mechanism of the irreversible inactivation of mouse ornithine decarboxylase by alpha-difluoromethylornithine. Characterization of sequences at the inhibitor and coenzyme binding sites. The Journal of biological chemistry, 1992, 267, (1), 150-158.

[77] Grishin, N.V.; Osterman, A.L.; Brooks, H.B.; Phillips, M.A.; Goldsmith, E.J., X-ray structure of ornithine decarboxylase from Trypanosoma brucei: the native structure and the structure in complex with alpha-difluoromethylornithine. Biochemistry, 1999, 38, (46), 1517415184.

[78] Iten, M.; Mett, H.; Evans, A.; Enyaru, J.C.; Brun, R.; Kaminsky, R., Alterations in ornithine decarboxylase characteristics account for tolerance of Trypanosoma brucei rhodesiense to D,L-alpha-difluoromethylornithine. Antimicrobial agents and chemotherapy, 1997, 41, (9), 1922-1925.

[79] Heby, O.; Roberts, S.C.; Ullman, B., Polyamine biosynthetic enzymes as drug targets in parasitic protozoa. Biochemical Society transactions, 2003, 31, (2), 415-419.

[80] Fairlamb, A.H.; Henderson, G.B.; Bacchi, C.J.; Cerami, A., In vivo effects of difluoromethylornithine on trypanothione and polyamine levels in bloodstream forms of Trypanosoma brucei. Molecular and biochemical parasitology, 1987, 24, (2), 185-191.

[81] Bacchi, C.J.; Yarlett, N., Effects of antagonists of polyamine metabolism on African trypanosomes. Acta tropica, 1993, 54, (3-4), 225-236.

[82] Xiao, Y.; McCloskey, D.E.; Phillips, M.A., RNA interference-mediated silencing of ornithine decarboxylase and spermidine synthase genes in Trypanosoma brucei provides insight into regulation of polyamine biosynthesis. Eukaryotic cell, 2009, 8, (5), 747-755. 
[83] Heby, O.; Persson, L.; Rentala, M., Targeting the polyamine biosynthetic enzymes: a promising approach to therapy of African sleeping sickness, Chagas' disease, and leishmaniasis. Amino acids, 2007, 33, (2), 359-366.

[84] Yarlett, N.; Bacchi, C.J., Effect of DL-alpha-difluoromethylornithine on methionine cycle intermediates in Trypanosoma brucei brucei. Molecular and biochemical parasitology, 1988, 27, (1), 1-10.

[85] Bitonti, A.J.; Cross-Doersen, D.E.; McCann, P.P., Effects of alphadifluoromethylornithine on protein synthesis and synthesis of the variant-specific glycoprotein (VSG) in Trypanosoma brucei brucei. The Biochemical journal, 1988, 250, (1), 295-298.

[86] Giffin, B.F.; McCann, P.P.; Bitonti, A.J.; Bacchi, C.J., Polyamine depletion following exposure to DL-alpha-difluoromethylornithine both in vivo and in vitro initiates morphological alterations and mitochondrial activation in a monomorphic strain of Trypanosoma brucei brucei. The Journal of protozoology, 1986, 33, (2), 238-243.

[87] Vincent, I.M.; Creek, D.; Watson, D.G.; Kamleh, M.A.; Woods, D.J.; Wong, P.E.; Burchmore, R.J.; Barrett, M.P., A molecular mechanism for eflornithine resistance in African trypanosomes. PLoS pathogens, 2010, 6, (11), e1001204.

[88] Baker, N.; Alsford, S.; Horn, D., Genome-wide RNAi screens in African trypanosomes identify the nifurtimox activator NTR and the eflornithine transporter AAT6. Molecular and biochemical parasitology, 2011, 176, (1), 55-57.

[89] Schumann Burkard, G.; Jutzi, P.; Roditi, I., Genome-wide RNAi screens in bloodstream form trypanosomes identify drug transporters. Molecular and biochemical parasitology, 2011, 175, (1), 91-94.

[90] Priotto, G.; Kasparian, S.; Mutombo, W.; Ngouama, D.; Ghorashian, S.; Arnold, U.; Ghabri, S.; Baudin, E.; Buard, V.; Kazadi-Kyanza, S.; Ilunga, M.; Mutangala, W.; Pohlig, G.; Schmid, C.; Karunakara, U.; Torreele, E.; Kande, V., Nifurtimox-eflornithine combination therapy for second-stage African Trypanosoma brucei gambiense trypanosomiasis: a multicentre, randomised, phase III, non-inferiority trial. Lancet, 2009, 374, (9683), 56-64.

[91] Opigo, J.; Woodrow, C., NECT trial: more than a small victory over sleeping sickness. Lancet, 2009, 374, (9683), 7-9.

[92] Yun, O.; Priotto, G.; Tong, J.; Flevaud, L.; Chappuis, F., NECT is next: implementing the new drug combination therapy for Trypanosoma brucei gambiense sleeping sickness. PLoS neglected tropical diseases, 2010, 4, (5), e720.

[93] Phillips, M.A., Stoking the drug target pipeline for human African trypanosomiasis. Molecular microbiology, 2012, 86, (1), 10-14.

[94] Alirol, E.; Schrumpf, D.; Amici Heradi, J.; Riedel, A.; de Patoul, C.; Quere, M.; Chappuis, F., Nifurtimox-eflornithine combination therapy for second-stage gambiense human African trypanosomiasis: Medecins Sans Frontieres experience in the Democratic Republic of the Congo. Clinical infectious diseases : an official publication of the Infectious Diseases Society of America, 2013, 56, (2), 195-203.

[95] Wilkinson, S.R.; Taylor, M.C.; Horn, D.; Kelly, J.M.; Cheeseman, I., A mechanism for cross-resistance to nifurtimox and benznidazole in trypanosomes. Proc Natl Acad Sci U S A, 2008, 105, (13), 5022-5027.

[96] Tarral, A.; Blesson, S.; Mordt, O.V.; Torreele, E.; Sassella, D.; Bray, M.A.; Hovsepian, L.; Evene, E.; Gualano, V.; Felices, M.; Strub-Wourgaft, N., Determination of an 
optimal dosing regimen for fexinidazole, a novel oral drug for the treatment of human African trypanosomiasis: first-in-human studies. Clinical pharmacokinetics, 2014, 53, (6), 565-580.

[97] Torreele, E.; Bourdin Trunz, B.; Tweats, D.; Kaiser, M.; Brun, R.; Mazue, G.; Bray, M.A.; Pecoul, B., Fexinidazole--a new oral nitroimidazole drug candidate entering clinical development for the treatment of sleeping sickness. PLoS neglected tropical diseases, 2010 , 4, (12), e923.

[98] Kaiser, M.; Bray, M.A.; Cal, M.; Bourdin Trunz, B.; Torreele, E.; Brun, R., Antitrypanosomal activity of fexinidazole, a new oral nitroimidazole drug candidate for treatment of sleeping sickness. Antimicrobial agents and chemotherapy, 2011, 55, (12), 56025608.

[99] Wyllie, S.; Patterson, S.; Stojanovski, L.; Simeons, F.R.; Norval, S.; Kime, R.; Read, K.D.; Fairlamb, A.H., The anti-trypanosome drug fexinidazole shows potential for treating visceral leishmaniasis. Science translational medicine, 2012, 4, (119), 119 re111.

[100] Sokolova, A.Y.; Wyllie, S.; Patterson, S.; Oza, S.L.; Read, K.D.; Fairlamb, A.H., Cross-resistance to nitro drugs and implications for treatment of human African trypanosomiasis. Antimicrobial agents and chemotherapy, 2010, 54, (7), 2893-2900.

[101] Zingales, B.; Miles, M.A.; Campbell, D.A.; Tibayrenc, M.; Macedo, A.M.; Teixeira, M.M.; Schijman, A.G.; Llewellyn, M.S.; Lages-Silva, E.; Machado, C.R.; Andrade, S.G.; Sturm, N.R., The revised Trypanosoma cruzi subspecific nomenclature: rationale, epidemiological relevance and research applications. Infection, genetics and evolution : journal of molecular epidemiology and evolutionary genetics in infectious diseases, 2012, 12, (2), 240-253.

[102] Schofield, C.J.; Jannin, J.; Salvatella, R., The future of Chagas disease control. Trends in parasitology, 2006, 22, (12), 583-588.

[103] WHO Chagas disease (American trypanosomiasis). Fact sheet N³40.; World Health Organization: Geneva, Updated March 2015, 2015.

[104] Bern, C.; Kjos, S.; Yabsley, M.J.; Montgomery, S.P., Trypanosoma cruzi and Chagas' Disease in the United States. Clinical microbiology reviews, 2011, 24, (4), 655-681.

[105] Gascon, J.; Bern, C.; Pinazo, M.J., Chagas disease in Spain, the United States and other non-endemic countries. Acta tropica, 2010, 115, (1-2), 22-27.

[106] Jackson, Y.; Pinto, A.; Pett, S., Chagas disease in Australia and New Zealand: risks and needs for public health interventions. Tropical medicine \& international health : TM \& IH, 2014, 19, (2), 212-218.

[107] Navarro, M.; Navaza, B.; Guionnet, A.; Lopez-Velez, R., Chagas disease in Spain: need for further public health measures. PLoS neglected tropical diseases, 2012, 6, (12), e1962.

[108] Rassi, A., Jr.; Rassi, A.; Marcondes de Rezende, J., American trypanosomiasis (Chagas disease). Infectious disease clinics of North America, 2012, 26, (2), 275-291.

[109] Correa, P.R.; Cordero, E.M.; Gentil, L.G.; Bayer-Santos, E.; da Silveira, J.F., Genetic structure and expression of the surface glycoprotein GP82, the main adhesin of Trypanosoma cruzi metacyclic trypomastigotes. TheScientificWorldJournal, 2013, 2013, 156734.

[110] Steverding, D., The history of Chagas disease. Parasites \& vectors, 2014, 7, 317. 
[111] Blum, J.A.; Zellweger, M.J.; Burri, C.; Hatz, C., Cardiac involvement in African and American trypanosomiasis. The Lancet infectious diseases, 2008, 8, (10), 631-641.

[112] Chatelain, E., Chagas disease drug discovery: toward a new era. J Biomol Screen, 2015, 20, (1), 22-35.

[113] Ayub-Ferreira, S.M.; Mangini, S.; Issa, V.S.; Cruz, F.D.; Bacal, F.; Guimaraes, G.V.; Chizzola, P.R.; Conceicao-Souza, G.E.; Marcondes-Braga, F.G.; Bocchi, E.A., Mode of death on Chagas heart disease: comparison with other etiologies. a subanalysis of the REMADHE prospective trial. PLoS neglected tropical diseases, 2013, 7, (4), e2176.

[114] Rodriques Coura, J.; de Castro, S.L., A critical review on Chagas disease chemotherapy. Mem Inst Oswaldo Cruz, 2002, 97, (1), 3-24.

[115] Mejia-Jaramillo, A.M.; Fernandez, G.J.; Palacio, L.; Triana-Chavez, O., Gene expression study using real-time PCR identifies an NTR gene as a major marker of resistance to benzonidazole in Trypanosoma cruzi. Parasites \& vectors, 2011, 4, 169.

[116] Coura, J.R., Present situation and new strategies for Chagas disease chemotherapy: a proposal. Mem Inst Oswaldo Cruz, 2009, 104, (4), 549-554.

[117] Polak, A.; Richle, R., Mode of action of the 2-nitroimidazole derivative benznidazole. Ann Trop Med Parasitol, 1978, 72, (1), 45-54.

[118] Diaz de Toranzo, E.G.; Castro, J.A.; Franke de Cazzulo, B.M.; Cazzulo, J.J., Interaction of benznidazole reactive metabolites with nuclear and kinetoplastic DNA, proteins and lipids from Trypanosoma cruzi. Experientia, 1988, 44, (10), 880-881.

[119] Docampo, R.; Moreno, S.N., Free radical metabolism of antiparasitic agents. Fed Proc, 1986, 45, (10), 2471-2476.

[120] Hall, B.S.; Bot, C.; Wilkinson, S.R., Nifurtimox activation by trypanosomal type I nitroreductases generates cytotoxic nitrile metabolites. J Biol Chem, 2011, 286, (15), 1308813095.

[121] Ashford, R.W., The leishmaniases as emerging and reemerging zoonoses. International journal for parasitology, 2000, 30, (12-13), 1269-1281.

[122] Croan, D.G.; Morrison, D.A.; Ellis, J.T., Evolution of the genus Leishmania revealed by comparison of DNA and RNA polymerase gene sequences. Mol Biochem Parasitol, 1997, $89,(2), 149-159$.

[123] Noyes, H.; Pratlong, F.; Chance, M.; Ellis, J.; Lanotte, G.; Dedet, J.P., A previously unclassified trypanosomatid responsible for human cutaneous lesions in Martinique (French West Indies) is the most divergent member of the genus Leishmania ss. Parasitology, 2002, 124, (Pt 1), 17-24.

[124] Lainson, R.; Ward, R.D.; Shaw, J.J., Leishmania in phlebotomid sandflies: VI. Importance of hindgut development in distinguishing between parasites of the Leishmania mexicana and L. braziliensis complexes. Proceedings of the Royal Society of London. Series B, Biological sciences, 1977, 199, (1135), 309-320.

[125] Kaye, P.; Scott, P., Leishmaniasis: complexity at the host-pathogen interface. Nat Rev Microbiol, 2011, 9, (8), 604-615.

[126] WHO Control of Leishmaniases: report of a meeting of the WHO Expert Committee; World Health Organization: Geneva, 2010. 
[127] Banuls, A.L.; Hide, M.; Prugnolle, F., Leishmania and the leishmaniases: a parasite genetic update and advances in taxonomy, epidemiology and pathogenicity in humans. Adv Parasitol, 2007, 64, 1-109.

[128] Campino, L.; Santos-Gomes, G.M.; Pratlong, F.; Antunes, F.; Mauricio, I.; Dedet, J.P.; Abranches, P., HIV/Leishmania co-infections in Portugal: diagnosis and isoenzyme characterization of Leishmania. Annals of tropical medicine and parasitology, 1997, 91, (4), 433-436.

[129] Hide, M.; Bucheton, B.; Kamhawi, S.; Bras-Goncalves, R.; Sundar, S.; Lemesre, J.L.; Banuls, A.L. Understanding Human Leishmaniasis: The need or an Integrated Approach. Wiley-Liss, Hoboken, N.J.: Encyclopedia of Infectious Diseases: Modern Methodologies, 2007.

[130] WHO Leishmaniasis. Fact sheet No375.; World Health Organization: Geneva, February 2015, 2015.

\section{[131] WHO WHO Report on Global Surveillance of Epidemic-pronelnfectious Diseases}

WHO/CDS/CSR/ISR/2000.1; World Health Organization Department of Communicable Disease Surveillance and Response: 2000.

[132] Lopez-Velez, R.; Perez-Molina, J.A.; Guerrero, A.; Baquero, F.; Villarrubia, J.; Escribano, L.; Bellas, C.; Perez-Corral, F.; Alvar, J., Clinicoepidemiologic characteristics, prognostic factors, and survival analysis of patients coinfected with human immunodeficiency virus and Leishmania in an area of Madrid, Spain. Am J Trop Med Hyg, 1998, 58, (4), 436443.

[133] Herwaldt, B.L., Leishmaniasis. Lancet, 1999, 354, (9185), 1191-1199.

[134] Sharma, U.; Singh, S., Insect vectors of Leishmania: distribution, physiology and their control. Journal of vector borne diseases, 2008, 45, (4), 255-272.

[135] Murray, H.W.; Berman, J.D.; Davies, C.R.; Saravia, N.G., Advances in leishmaniasis. Lancet, 2005, 366, (9496), 1561-1577.

[136] Morillas-Marquez, F.; Martin-Sanchez, J.; Acedo-Sanchez, C.; Pineda, J.A.; Macias, J.; Sanjuan-Garcia, J., Leishmania infantum (Protozoa, kinetoplastida): transmission from infected patients to experimental animal under conditions that simulate needle-sharing. Experimental parasitology, 2002, 100, (1), 71-74.

[137] Cruz, I.; Morales, M.A.; Noguer, I.; Rodriguez, A.; Alvar, J., Leishmania in discarded syringes from intravenous drug users. Lancet, 2002, 359, (9312), 1124-1125.

[138] Pagliano, P.; Carannante, N.; Rossi, M.; Gramiccia, M.; Gradoni, L.; Faella, F.S.; Gaeta, G.B., Visceral leishmaniasis in pregnancy: a case series and a systematic review of the literature. J Antimicrob Chemother, 2005, 55, (2), 229-233.

[139] Spickler, A. Emerging and Exotic Diseases of Animals Textbook. 4th edition ed. CFSPH/IICAB, lowa State University, Ames (IA), 2010.

[140] Rogers, M.E.; Ilg, T.; Nikolaev, A.V.; Ferguson, M.A.; Bates, P.A., Transmission of cutaneous leishmaniasis by sand flies is enhanced by regurgitation of fPPG. Nature, 2004, 430, (6998), 463-467. 
[141] Rogers, M.E.; Hajmova, M.; Joshi, M.B.; Sadlova, J.; Dwyer, D.M.; Volf, P.; Bates, P.A., Leishmania chitinase facilitates colonization of sand fly vectors and enhances transmission to mice. Cell Microbiol, 2008, 10, (6), 1363-1372.

[142] Molly, M.-A. Leishmaniasis: A review of the disease and the debate over the origin and dispersal of the causaitive parasite Leishmania; Macalester Reviews in Biogeography, 2008.

[143] Chappuis, F.; Sundar, S.; Hailu, A.; Ghalib, H.; Rijal, S.; Peeling, R.W.; Alvar, J.; Boelaert, M., Visceral leishmaniasis: what are the needs for diagnosis, treatment and control? Nat Rev Microbiol, 2007, 5, (11), 873-882.

[144] Alvar, J.; Velez, I.D.; Bern, C.; Herrero, M.; Desjeux, P.; Cano, J.; Jannin, J.; den Boer, M.; Team, W.H.O.L.C., Leishmaniasis worldwide and global estimates of its incidence. PLoS One, 2012, 7, (5), e35671.

[145] David, C.V.; Craft, N., Cutaneous and mucocutaneous leishmaniasis. Dermatol Ther, 2009, 22, (6), 491-502.

[146] Ronet, C.; Beverley, S.M.; Fasel, N., Muco-cutaneous leishmaniasis in the New World: the ultimate subversion. Virulence, 2011, 2, (6), 547-552.

[147] Hartley, M.A.; Ronet, C.; Zangger, H.; Beverley, S.M.; Fasel, N., Leishmania RNA virus: when the host pays the toll. Front Cell Infect Microbiol, 2012, 2, 99.

[148] Ramesh, V., Post-kala-azar dermal leishmaniasis with visceral leishmaniasis, or a rare presentation of visceral leishmaniasis with extensive skin manifestations. Int $J$ Dermatol, 2007, 46, (12), 1326.

[149] Croft, S.L., PKDL--a drug related phenomenon? Indian J Med Res, 2008, 128, (1), 10-11.

[150] Mutiso, J.M.; Macharia, J.C.; Kiio, M.N.; Ichagichu, J.M.; Rikoi, H.; Gicheru, M.M., Development of Leishmania vaccines: predicting the future from past and present experience. Journal of biomedical research, 2013, 27, (2), 85-102.

[151] Baneth, G.; Shaw, S.E., Chemotherapy of canine leishmaniosis. Veterinary parasitology, 2002, 106, (4), 315-324.

[152] Tiuman, T.S.; Santos, A.O.; Ueda-Nakamura, T.; Filho, B.P.; Nakamura, C.V., Recent advances in leishmaniasis treatment. International journal of infectious diseases : IJID : official publication of the International Society for Infectious Diseases, 2011, 15, (8), e525532.

[153] Berman, J., Miltefosine to treat leishmaniasis. Expert opinion on pharmacotherapy, 2005, 6, (8), 1381-1388.

[154] Goodwin, L.G., Pentostam (sodium stibogluconate); a 50-year personal reminiscence. Trans R Soc Trop Med Hyg, 1995, 89, (3), 339-341.

[155] Thakur, C.P.; Narayan, S.; Ranjan, A., Epidemiological, clinical \& pharmacological study of antimony-resistant visceral leishmaniasis in Bihar, India. Indian J Med Res, 2004, 120, (3), 166-172.

[156] Goto, H.; Lindoso, J.A., Current diagnosis and treatment of cutaneous and mucocutaneous leishmaniasis. Expert Rev Anti Infect Ther, 2010, 8, (4), 419-433.

\section{.}


[157] Ferreira Cdos, S.; Martins, P.S.; Demicheli, C.; Brochu, C.; Ouellette, M.; Frezard, F., Thiol-induced reduction of antimony(V) into antimony(III): a comparative study with trypanothione, cysteinyl-glycine, cysteine and glutathione. Biometals, 2003, 16, (3), 441-446.

[158] Frezard, F.; Demicheli, C.; Ribeiro, R.R., Pentavalent antimonials: new perspectives for old drugs. Molecules, 2009, 14, (7), 2317-2336.

[159] Gourbal, B.; Sonuc, N.; Bhattacharjee, H.; Legare, D.; Sundar, S.; Ouellette, M.; Rosen, B.P.; Mukhopadhyay, R., Drug uptake and modulation of drug resistance in Leishmania by an aquaglyceroporin. J Biol Chem, 2004, 279, (30), 31010-31017.

[160] Denton, H.; McGregor, J.C.; Coombs, G.H., Reduction of anti-leishmanial pentavalent antimonial drugs by a parasite-specific thiol-dependent reductase, TDR1. Biochem J, 2004, 381, (Pt 2), 405-412.

[161] Sudhandiran, G.; Shaha, C., Antimonial-induced increase in intracellular Ca2+ through non-selective cation channels in the host and the parasite is responsible for apoptosis of intracellular Leishmania donovani amastigotes. J Biol Chem, 2003, 278, (27), 25120-25132.

[162] Cunningham, M.L.; Fairlamb, A.H., Trypanothione reductase from Leishmania donovani. Purification, characterisation and inhibition by trivalent antimonials. Eur $\mathrm{J}$ Biochem, 1995, 230, (2), 460-468.

[163] Demicheli, C.; Frezard, F.; Mangrum, J.B.; Farrell, N.P., Interaction of trivalent antimony with a $\mathrm{CCHC}$ zinc finger domain: potential relevance to the mechanism of action of antimonial drugs. Chem Commun (Camb), 2008, (39), 4828-4830.

[164] Wyllie, S.; Cunningham, M.L.; Fairlamb, A.H., Dual action of antimonial drugs on thiol redox metabolism in the human pathogen Leishmania donovani. J Biol Chem, 2004, 279, (38), 39925-39932.

[165] Croft, S.L.; Seifert, K.; Yardley, V., Current scenario of drug development for leishmaniasis. Indian J Med Res, 2006, 123, (3), 399-410.

[166] Ouellette, M.; Drummelsmith, J.; Papadopoulou, B., Leishmaniasis: drugs in the clinic, resistance and new developments. Drug Resist Updat, 2004, 7, (4-5), 257-266.

[167] dos Santos Ferreira, C.; de Castro Pimenta, A.M.; Demicheli, C.; Frezard, F., Characterization of reactions of antimoniate and meglumine antimoniate with a guanine ribonucleoside at different $\mathrm{pH}$. Biometals, 2006, 19, (5), 573-581.

[168] Leprohon, P.; Legare, D.; Raymond, F.; Madore, E.; Hardiman, G.; Corbeil, J.; Ouellette, M., Gene expression modulation is associated with gene amplification, supernumerary chromosomes and chromosome loss in antimony-resistant Leishmania infantum. Nucleic Acids Res, 2009, 37, (5), 1387-1399.

[169] Singh, N.; Almeida, R.; Kothari, H.; Kumar, P.; Mandal, G.; Chatterjee, M.; Venkatachalam, S.; Govind, M.K.; Mandal, S.K.; Sundar, S., Differential gene expression analysis in antimony-unresponsive Indian kala azar (visceral leishmaniasis) clinical isolates by DNA microarray. Parasitology, 2007, 134, (Pt 6), 777-787.

[170] Vergnes, B.; Gourbal, B.; Girard, I.; Sundar, S.; Drummelsmith, J.; Ouellette, M., A proteomics screen implicates HSP83 and a small kinetoplastid calpain-related protein in drug resistance in Leishmania donovani clinical field isolates by modulating drug-induced programmed cell death. Mol Cell Proteomics, 2007, 6, (1), 88-101. 
[171] Legare, D.; Cayer, S.; Singh, A.K.; Richard, D.; Papadopoulou, B.; Ouellette, M., ABC proteins of Leishmania. J Bioenerg Biomembr, 2001, 33, (6), 469-474.

[172] Garg, M.; Goyal, N., MAPK1 of Leishmania donovani modulates antimony susceptibility by downregulating P-glycoprotein efflux pumps. Antimicrob Agents Chemother, 2015, 59, (7), 3853-3863.

[173] Haldar, A.K.; Sen, P.; Roy, S., Use of antimony in the treatment of leishmaniasis: current status and future directions. Mol Biol Int, 2011, 2011, 571242.

[174] Rai, S.; Bhaskar; Goel, S.K.; Nath Dwivedi, U.; Sundar, S.; Goyal, N., Role of efflux pumps and intracellular thiols in natural antimony resistant isolates of Leishmania donovani. PLoS One, 2013, 8, (9), e74862.

[175] Vanlerberghe, V.; Diap, G.; Guerin, P.J.; Meheus, F.; Gerstl, S.; Van der Stuyft, P.; Boelaert, M., Drug policy for visceral leishmaniasis: a cost-effectiveness analysis. Trop Med Int Health, 2007, 12, (2), 274-283.

[176] Berman, J.D.; Goad, L.J.; Beach, D.H.; Holz, G.G., Jr., Effects of ketoconazole on sterol biosynthesis by Leishmania mexicana mexicana amastigotes in murine macrophage tumor cells. Mol Biochem Parasitol, 1986, 20, (1), 85-92.

[177] Bern, C.; Adler-Moore, J.; Berenguer, J.; Boelaert, M.; den Boer, M.; Davidson, R.N.; Figueras, C.; Gradoni, L.; Kafetzis, D.A.; Ritmeijer, K.; Rosenthal, E.; Royce, C.; Russo, R.; Sundar, S.; Alvar, J., Liposomal amphotericin B for the treatment of visceral leishmaniasis. Clin Infect Dis, 2006, 43, (7), 917-924.

[178] Ellis, M.; Bernsen, R.; Ali-Zadeh, H.; Kristensen, J.; Hedstrom, U.; Poughias, L.; Bresnik, M.; Al-Essa, A.; Stevens, D.A., A safety and feasibility study comparing an intermittent high dose with a daily standard dose of liposomal amphotericin B for persistent neutropenic fever. J Med Microbiol, 2009, 58, (Pt 11), 1474-1485.

[179] Sundar, S.; Chatterjee, M., Visceral leishmaniasis - current therapeutic modalities. Indian J Med Res, 2006, 123, (3), 345-352.

[180] Sundar, S.; Maurya, R.; Singh, R.K.; Bharti, K.; Chakravarty, J.; Parekh, A.; Rai, M.; Kumar, K.; Murray, H.W., Rapid, noninvasive diagnosis of visceral leishmaniasis in India: comparison of two immunochromatographic strip tests for detection of anti-K39 antibody. $J$ Clin Microbiol, 2006, 44, (1), 251-253.

[181] Laniado-Laborin, R.; Cabrales-Vargas, M.N., Amphotericin B: side effects and toxicity. Rev Iberoam Micol, 2009, 26, (4), 223-227.

[182] Meyerhoff, A., U.S. Food and Drug Administration approval of AmBisome (liposomal amphotericin B) for treatment of visceral leishmaniasis. Clin Infect Dis, 1999, 28, (1), 42-48; discussion 49-51.

[183] Sundar, S., Diagnosis of kala-azar--an important stride. J Assoc Physicians India, 2003, 51, 753-755.

[184] Murray, H.W., Progress in the treatment of a neglected infectious disease: visceral leishmaniasis. Expert Rev Anti Infect Ther, 2004, 2, (2), 279-292.

[185] Sundar, S.; Jha, T.K.; Thakur, C.P.; Engel, J.; Sindermann, H.; Fischer, C.; Junge, K.; Bryceson, A.; Berman, J., Oral miltefosine for Indian visceral leishmaniasis. N Engl J Med, 2002, 347, (22), 1739-1746. 
[186] Sundar, S.; Rai, M., Advances in the treatment of leishmaniasis. Curr Opin Infect Dis, 2002, 15, (6), 593-598.

[187] Thakur, C.P.; Pandey, A.K.; Sinha, G.P.; Roy, S.; Behbehani, K.; Olliaro, P., Comparison of three treatment regimens with liposomal amphotericin B (AmBisome) for visceral leishmaniasis in India: a randomized dose-finding study. Trans $R$ Soc Trop Med Hyg, 1996, 90, (3), 319-322.

[188] Paila, Y.D.; Saha, B.; Chattopadhyay, A., Amphotericin B inhibits entry of Leishmania donovani into primary macrophages. Biochem Biophys Res Commun, 2010, 399, (3), 429433.

[189] Ramos, H.; Valdivieso, E.; Gamargo, M.; Dagger, F.; Cohen, B.E., Amphotericin B kills unicellular leishmanias by forming aqueous pores permeable to small cations and anions. J Membr Biol, 1996, 152, (1), 65-75.

[190] Brotherton, M.C.; Bourassa, S.; Legare, D.; Poirier, G.G.; Droit, A.; Ouellette, M., Quantitative proteomic analysis of amphotericin B resistance in Leishmania infantum. Int $J$ Parasitol Drugs Drug Resist, 2014, 4, (2), 126-132.

[191] Mbongo, N.; Loiseau, P.M.; Billion, M.A.; Robert-Gero, M., Mechanism of amphotericin B resistance in Leishmania donovani promastigotes. Antimicrob Agents Chemother, 1998, 42, (2), 352-357.

[192] Pourshafie, M.; Morand, S.; Virion, A.; Rakotomanga, M.; Dupuy, C.; Loiseau, P.M., Cloning of S-adenosyl-L-methionine:C-24-Delta-sterol-methyltransferase (ERG6) from Leishmania donovani and characterization of mRNAs in wild-type and amphotericin BResistant promastigotes. Antimicrob Agents Chemother, 2004, 48, (7), 2409-2414.

[193] Purkait, B.; Kumar, A.; Nandi, N.; Sardar, A.H.; Das, S.; Kumar, S.; Pandey, K.; Ravidas, V.; Kumar, M.; De, T.; Singh, D.; Das, P., Mechanism of amphotericin B resistance in clinical isolates of Leishmania donovani. Antimicrob Agents Chemother, 2012, 56, (2), 10311041.

[194] Gazanion, E.; Fernandez-Prada, C.; Papadopoulou, B.; Leprohon, P.; Ouellette, M., Cos-Seq for high-throughput identification of drug target and resistance mechanisms in the protozoan parasite Leishmania. Proc Natl Acad Sci U S A, 2016, 113, (21), E3012-3021.

[195] Singh, K.; Ali, V.; Pratap Singh, K.; Gupta, P.; Suman, S.S.; Ghosh, A.K.; Bimal, S.; Pandey, K.; Das, P., Deciphering the interplay between cysteine synthase and thiol cascade proteins in modulating Amphotericin $B$ resistance and survival of Leishmania donovani under oxidative stress. Redox Biol, 2017, 12, 350-366.

[196] Castillo, E.; Dea-Ayuela, M.A.; Bolas-Fernandez, F.; Rangel, M.; Gonzalez-Rosende, M.E., The kinetoplastid chemotherapy revisited: current drugs, recent advances and future perspectives. Curr Med Chem, 2010, 17, (33), 4027-4051.

[197] Berman, J.J., Treatment of leishmaniasis with miltefosine: 2008 status. Expert Opin Drug Metab Toxicol, 2008, 4, (9), 1209-1216.

[198] Croft, S.L.; Engel, J., Miltefosine--discovery of the antileishmanial activity of phospholipid derivatives. Trans R Soc Trop Med Hyg, 2006, 100 Suppl 1, S4-8.

[199] Ritmeijer, K.; Dejenie, A.; Assefa, Y.; Hundie, T.B.; Mesure, J.; Boots, G.; den Boer, M.; Davidson, R.N., A comparison of miltefosine and sodium stibogluconate for treatment of visceral leishmaniasis in an Ethiopian population with high prevalence of HIV infection. Clin Infect Dis, 2006, 43, (3), 357-364. 
[200] Sindermann, H.; Engel, J., Development of miltefosine as an oral treatment for leishmaniasis. Trans R Soc Trop Med Hyg, 2006, 100 Suppl 1, S17-20.

[201] Troya, J.; Casquero, A.; Refoyo, E.; Fernandez-Guerrero, M.L.; Gorgolas, M., Long term failure of miltefosine in the treatment of refractory visceral leishmaniasis in AIDS patients. Scand J Infect Dis, 2008, 40, (1), 78-80.

[202] Seifert, K., Structures, targets and recent approaches in anti-leishmanial drug discovery and development. Open Med Chem J, 2011, 5, 31-39.

[203] Bhattacharya, S.K.; Sinha, P.K.; Sundar, S.; Thakur, C.P.; Jha, T.K.; Pandey, K.; Das, V.R.; Kumar, N.; Lal, C.; Verma, N.; Singh, V.P.; Ranjan, A.; Verma, R.B.; Anders, G.; Sindermann, H.; Ganguly, N.K., Phase 4 trial of miltefosine for the treatment of Indian visceral leishmaniasis. J Infect Dis, 2007, 196, (4), 591-598.

[204] Marinho Fde, A.; Goncalves, K.C.; Oliveira, S.S.; Oliveira, A.C.; Bellio, M.; d'AvilaLevy, C.M.; Santos, A.L.; Branquinha, M.H., Miltefosine induces programmed cell death in Leishmania amazonensis promastigotes. Mem Inst Oswaldo Cruz, 2011, 106, (4), 507-509.

[205] Paris, C.; Loiseau, P.M.; Bories, C.; Breard, J., Miltefosine induces apoptosis-like death in Leishmania donovani promastigotes. Antimicrob Agents Chemother, 2004, 48, (3), 852-859.

[206] Verma, N.K.; Dey, C.S., Possible mechanism of miltefosine-mediated death of Leishmania donovani. Antimicrob Agents Chemother, 2004, 48, (8), 3010-3015.

[207] Verma, N.K.; Singh, G.; Dey, C.S., Miltefosine induces apoptosis in arsenite-resistant Leishmania donovani promastigotes through mitochondrial dysfunction. Exp Parasitol, 2007, 116, (1), 1-13.

[208] Lux, H.; Hart, D.T.; Parker, P.J.; Klenner, T., Ether lipid metabolism, GPI anchor biosynthesis, and signal transduction are putative targets for anti-leishmanial alkyl phospholipid analogues. Adv Exp Med Biol, 1996, 416, 201-211.

[209] Lux, H.; Heise, N.; Klenner, T.; Hart, D.; Opperdoes, F.R., Ether--lipid (alkylphospholipid) metabolism and the mechanism of action of ether--lipid analogues in Leishmania. Mol Biochem Parasitol, 2000, 111, (1), 1-14.

[210] Perez-Victoria, F.J.; Sanchez-Canete, M.P.; Seifert, K.; Croft, S.L.; Sundar, S.; Castanys, S.; Gamarro, F., Mechanisms of experimental resistance of Leishmania to miltefosine: Implications for clinical use. Drug Resist Updat, 2006, 9, (1-2), 26-39.

[211] Srivastava, S.; Mishra, J.; Gupta, A.K.; Singh, A.; Shankar, P.; Singh, S., Laboratory confirmed miltefosine resistant cases of visceral leishmaniasis from India. Parasit Vectors, 2017, 10, (1), 49.

[212] Perez-Victoria, J.M.; Perez-Victoria, F.J.; Parodi-Talice, A.; Jimenez, I.A.; Ravelo, A.G.; Castanys, S.; Gamarro, F., Alkyl-lysophospholipid resistance in multidrug-resistant Leishmania tropica and chemosensitization by a novel P-glycoprotein-like transporter modulator. Antimicrob Agents Chemother, 2001, 45, (9), 2468-2474.

[213] Perez-Victoria, F.J.; Castanys, S.; Gamarro, F., Leishmania donovani resistance to miltefosine involves a defective inward translocation of the drug. Antimicrob Agents Chemother, 2003, 47, (8), 2397-2403. 
[214] Seifert, K.; Matu, S.; Javier Perez-Victoria, F.; Castanys, S.; Gamarro, F.; Croft, S.L., Characterisation of Leishmania donovani promastigotes resistant to hexadecylphosphocholine (miltefosine). Int J Antimicrob Agents, 2003, 22, (4), 380-387.

[215] Choudhury, K.; Zander, D.; Kube, M.; Reinhardt, R.; Clos, J., Identification of a Leishmania infantum gene mediating resistance to miltefosine and Sblll. Int J Parasitol, 2008, 38, (12), 1411-1423.

[216] Kulshrestha, A.; Sharma, V.; Singh, R.; Salotra, P., Comparative transcript expression analysis of miltefosine-sensitive and miltefosine-resistant Leishmania donovani. Parasitol Res, 2014, 113, (3), 1171-1184.

[217] Sundar, S.; Chakravarty, J., Paromomycin in the treatment of leishmaniasis. Expert Opin Investig Drugs, 2008, 17, (5), 787-794.

[218] Davidson, R.N.; den Boer, M.; Ritmeijer, K., Paromomycin. Trans R Soc Trop Med Hyg, 2009, 103, (7), 653-660.

[219] Olliaro, P.L.; Guerin, P.J.; Gerstl, S.; Haaskjold, A.A.; Rottingen, J.A.; Sundar, S., Treatment options for visceral leishmaniasis: a systematic review of clinical studies done in India, 1980-2004. Lancet Infect Dis, 2005, 5, (12), 763-774.

[220] Sundar, S.; Agrawal, N.; Arora, R.; Agarwal, D.; Rai, M.; Chakravarty, J., Shortcourse paromomycin treatment of visceral leishmaniasis in India: 14-day vs 21-day treatment. Clin Infect Dis, 2009, 49, (6), 914-918.

[221] Hailu, A.; Musa, A.; Wasunna, M.; Balasegaram, M.; Yifru, S.; Mengistu, G.; Hurissa, Z.; Hailu, W.; Weldegebreal, T.; Tesfaye, S.; Makonnen, E.; Khalil, E.; Ahmed, O.; Fadlalla, A.; El-Hassan, A.; Raheem, M.; Mueller, M.; Koummuki, Y.; Rashid, J.; Mbui, J.; Mucee, G.; Njoroge, S.; Manduku, V.; Musibi, A.; Mutuma, G.; Kirui, F.; Lodenyo, H.; Mutea, D.; Kirigi, G.; Edwards, T.; Smith, P.; Muthami, L.; Royce, C.; Ellis, S.; Alobo, M.; Omollo, R.; Kesusu, J.; Owiti, R.; Kinuthia, J.; Leishmaniasis East Africa Platform, g., Geographical variation in the response of visceral leishmaniasis to paromomycin in East Africa: a multicentre, open-label, randomized trial. PLoS Negl Trop Dis, 2010, 4, (10), e709.

[222] Garnier, T.; Croft, S.L., Topical treatment for cutaneous leishmaniasis. Curr Opin Investig Drugs, 2002, 3, (4), 538-544.

[223] El-On, J.; Bazarsky, E.; Sneir, R., Leishmania major: in vitro and in vivo antileishmanial activity of paromomycin ointment (Leshcutan) combined with the immunomodulator Imiquimod. Exp Parasitol, 2007, 116, (2), 156-162.

[224] Ben Salah, A.; Buffet, P.A.; Morizot, G.; Ben Massoud, N.; Zaatour, A.; Ben Alaya, N.; Haj Hamida, N.B.; El Ahmadi, Z.; Downs, M.T.; Smith, P.L.; Dellagi, K.; Grogl, M., WR279,396, a third generation aminoglycoside ointment for the treatment of Leishmania major cutaneous leishmaniasis: a phase 2, randomized, double blind, placebo controlled study. PLoS Negl Trop Dis, 2009, 3, (5), e432.

[225] Maarouf, M.; Lawrence, F.; Brown, S.; Robert-Gero, M., Biochemical alterations in paromomycin-treated Leishmania donovani promastigotes. Parasitol Res, 1997, 83, (2), 198202.

[226] el-On, J.; Sulitzeanu, A.; Schnur, L.F., Leishmania major: resistance of promastigotes to paromomycin, and susceptibility of amastigotes to paromomycinmethylbenzethonium chloride ointment. Ann Trop Med Parasitol, 1991, 85, (3), 323-328. 
[227] Fong, D.; Chan, M.M.; Rodriguez, R.; Gately, L.J.; Berman, J.D.; Grogl, M., Paromomycin resistance in Leishmania tropica: lack of correlation with mutation in the small subunit ribosomal RNA gene. Am J Trop Med Hyg, 1994, 51, (6), 758-766.

[228] Jhingran, A.; Chawla, B.; Saxena, S.; Barrett, M.P.; Madhubala, R., Paromomycin: uptake and resistance in Leishmania donovani. Mol Biochem Parasitol, 2009, 164, (2), 111 117.

[229] Bhandari, V.; Sundar, S.; Dujardin, J.C.; Salotra, P., Elucidation of cellular mechanisms involved in experimental paromomycin resistance in Leishmania donovani. Antimicrob Agents Chemother, 2014, 58, (5), 2580-2585.

[230] Llanos-Cuentas, A.; Echevarria, J.; Cruz, M.; La Rosa, A.; Campos, P.; Campos, M.; Franke, E.; Berman, J.; Modabber, F.; Marr, J., Efficacy of sodium stibogluconate alone and in combination with allopurinol for treatment of mucocutaneous leishmaniasis. Clin Infect Dis, 1997, 25, (3), 677-684.

[231] Berman, J.D., Human leishmaniasis: clinical, diagnostic, and chemotherapeutic developments in the last 10 years. Clin Infect Dis, 1997, 24, (4), 684-703.

[232] Navin, T.R.; Arana, B.A.; Arana, F.E.; Berman, J.D.; Chajon, J.F., Placebo-controlled clinical trial of sodium stibogluconate (Pentostam) versus ketoconazole for treating cutaneous leishmaniasis in Guatemala. J Infect Dis, 1992, 165, (3), 528-534.

[233] Rashid, J.R.; Wasunna, K.M.; Gachihi, G.S.; Nyakundi, P.M.; Mbugua, J.; Kirigi, G., The efficacy and safety of ketoconazole in visceral leishmaniasis. East Afr Med J, 1994, 71, (6), 392-395.

[234] Shakya, N.; Sane, S.A.; Vishwakarma, P.; Bajpai, P.; Gupta, S., Improved treatment of visceral leishmaniasis (kala-azar) by using combination of ketoconazole, miltefosine with an immunomodulator-Picroliv. Acta Trop, 2011, 119, (2-3), 188-193.

[235] LaFon, S.W.; Nelson, D.J.; Berens, R.L.; Marr, J.J., Inosine analogs. Their metabolism in mouse L cells and in Leishmania donovani. J Biol Chem, 1985, 260, (17), 96609665.

[236] Momeni, A.Z.; Reiszadae, M.R.; Aminjavaheri, M., Treatment of cutaneous leishmaniasis with a combination of allopurinol and low-dose meglumine antimoniate. Int $J$ Dermatol, 2002, 41, (7), 441-443.

[237] Ramesh, V.; Kumar, J.; Kumar, D.; Salotra, P., A retrospective study of intravenous sodium stibogluconate alone and in combinations with allopurinol, rifampicin, and an immunomodulator in the treatment of Indian post-kala-azar dermal leishmaniasis. Indian $J$ Dermatol Venereol Leprol, 2010, 76, (2), 138-144.

[238] Lopez-Martin, C.; Perez-Victoria, J.M.; Carvalho, L.; Castanys, S.; Gamarro, F., Sitamaquine sensitivity in Leishmania species is not mediated by drug accumulation in acidocalcisomes. Antimicrob Agents Chemother, 2008, 52, (11), 4030-4036.

[239] Loiseau, P.M.; Cojean, S.; Schrevel, J., Sitamaquine as a putative antileishmanial drug candidate: from the mechanism of action to the risk of drug resistance. Parasite, 2011, $18,(2), 115-119$.

[240] Reguera, R.M.; Calvo-Alvarez, E.; Alvarez-Velilla, R.; Balana-Fouce, R., Targetbased vs. phenotypic screenings in Leishmania drug discovery: A marriage of convenience or a dialogue of the deaf? Int J Parasitol Drugs Drug Resist, 2014, 4, (3), 355-357. 
[241] Michels, P.A.; Bringaud, F.; Herman, M.; Hannaert, V., Metabolic functions of glycosomes in trypanosomatids. Biochim Biophys Acta, 2006, 1763, (12), 1463-1477.

[242] Haanstra, J.R.; van Tuijl, A.; Kessler, P.; Reijnders, W.; Michels, P.A.; Westerhoff, H.V.; Parsons, M.; Bakker, B.M., Compartmentation prevents a lethal turbo-explosion of glycolysis in trypanosomes. Proc Natl Acad Sci U S A, 2008, 105, (46), 17718-17723.

[243] Kovarova, J.; Barrett, M.P., The Pentose Phosphate Pathway in Parasitic Trypanosomatids. Trends Parasitol, 2016, 32, (8), 622-634.

[244] Barrett, M.P., The pentose phosphate pathway and parasitic protozoa. Parasitol Today, 1997, 13, (1), 11-16.

[245] Stincone, A.; Prigione, A.; Cramer, T.; Wamelink, M.M.; Campbell, K.; Cheung, E.; Olin-Sandoval, V.; Gruening, N.M.; Krueger, A.; Tauqeer Alam, M.; Keller, M.A.; Breitenbach, M.; Brindle, K.M.; Rabinowitz, J.D.; Ralser, M., The return of metabolism: biochemistry and physiology of the pentose phosphate pathway. Biological reviews of the Cambridge Philosophical Society, 2014.

[246] Gupta, S.; Igoillo-Esteve, M.; Michels, P.A.; Cordeiro, A.T., Glucose-6-phosphate dehydrogenase of trypanosomatids: characterization, target validation, and drug discovery. Mol Biol Int, 2011, 2011, 135701.

[247] Comini, M.A., Ortíz, C. and Cazzulo, J. J. Drug Targets in Trypanosomal and Leishmanial Pentose Phosphate Pathway, in Trypanosomatid Diseases: Molecular Routes to Drug Discovery Wiley-VCH Verlag GmbH \& Co. KGaA, Weinheim, Germany, 2013.

[248] Duffieux, F.; Van Roy, J.; Michels, P.A.; Opperdoes, F.R., Molecular characterization of the first two enzymes of the pentose-phosphate pathway of Trypanosoma brucei. Glucose6-phosphate dehydrogenase and 6-phosphogluconolactonase. J Biol Chem, 2000, 275, (36), 27559-27565.

[249] Opperdoes, F.R.; Szikora, J.P., In silico prediction of the glycosomal enzymes of Leishmania major and trypanosomes. Mol Biochem Parasitol, 2006, 147, (2), 193-206.

[250] Mercaldi, G.F.; Dawson, A.; Hunter, W.N.; Cordeiro, A.T., The structure of a Trypanosoma cruzi glucose-6-phosphate dehydrogenase reveals differences from the mammalian enzyme. FEBS Lett, 2016, 590, (16), 2776-2786.

[251] Cordeiro, A.T.; Thiemann, O.H.; Michels, P.A., Inhibition of Trypanosoma brucei glucose-6-phosphate dehydrogenase by human steroids and their effects on the viability of cultured parasites. Bioorg Med Chem, 2009, 17, (6), 2483-2489.

[252] Ghosh, A.K.; Sardar, A.H.; Mandal, A.; Saini, S.; Abhishek, K.; Kumar, A.; Purkait, B.; Singh, R.; Das, S.; Mukhopadhyay, R.; Roy, S.; Das, P., Metabolic reconfiguration of the central glucose metabolism: a crucial strategy of Leishmania donovani for its survival during oxidative stress. FASEB J, 2015, 29, (5), 2081-2098.

[253] Gupta, S.; Cordeiro, A.T.; Michels, P.A., Glucose-6-phosphate dehydrogenase is the target for the trypanocidal action of human steroids. Mol Biochem Parasitol, 2011, 176, (2), 112-115.

[254] Duclert-Savatier, N.; Poggi, L.; Miclet, E.; Lopes, P.; Ouazzani, J.; Chevalier, N.; Nilges, M.; Delarue, M.; Stoven, V., Insights into the enzymatic mechanism of 6phosphogluconolactonase from Trypanosoma brucei using structural data and molecular dynamics simulation. J Mol Biol, 2009, 388, (5), 1009-1021. 
[255] Dickens, F.; Glock, G.E., Direct oxidation of glucose-6-phosphate, 6phosphogluconate and pentose-5-phosphates by enzymes of animal origin. Biochem J, 1951, 50, (1), 81-95.

[256] Giovannini, P.P.; Rippa, M.; Dallocchio, F.; Tetaud, M.; Barrett, M.P.; Hanau, S., The cross-linking by o-phthalaldehyde of two amino acid residues at the active site of 6phosphogluconate dehydrogenase. Biochem Mol Biol Int, 1997, 43, (1), 153-160.

[257] Heise, N.; Opperdoes, F.R., Purification, localisation and characterisation of glucose6-phosphate dehydrogenase of Trypanosoma brucei. Mol Biochem Parasitol, 1999, 99, (1), 21-32.

[258] Sorensen, K.I.; Hove-Jensen, B., Ribose catabolism of Escherichia coli: characterization of the rpiB gene encoding ribose phosphate isomerase $B$ and of the rpiR gene, which is involved in regulation of rpiB expression. J Bacteriol, 1996, 178, (4), 10031011.

[259] Huck, J.H.; Verhoeven, N.M.; Struys, E.A.; Salomons, G.S.; Jakobs, C.; van der Knaap, M.S., Ribose-5-phosphate isomerase deficiency: new inborn error in the pentose phosphate pathway associated with a slowly progressive leukoencephalopathy. Am J Hum Genet, 2004, 74, (4), 745-751.

[260] Cronin, C.N.; Nolan, D.P.; Voorheis, H.P., The enzymes of the classical pentose phosphate pathway display differential activities in procyclic and bloodstream forms of Trypanosoma brucei. FEBS Lett, 1989, 244, (1), 26-30.

[261] Faria, J.; Loureiro, I.; Santarem, N.; Cecilio, P.; Macedo-Ribeiro, S.; Tavares, J.; Cordeiro-da-Silva, A., Disclosing the essentiality of ribose-5-phosphate isomerase $B$ in Trypanosomatids. Sci Rep, 2016, 6, 26937.

[262] Kaur, P.K.; Dinesh, N.; Soumya, N.; Babu, N.K.; Singh, S., Identification and characterization of a novel Ribose 5-phosphate isomerase B from Leishmania donovani. Biochem Biophys Res Commun, 2012, 421, (1), 51-56.

[263] Loureiro, I.; Faria, J.; Clayton, C.; Macedo-Ribeiro, S.; Santarem, N.; Roy, N.; Cordeiro-da-Siva, A.; Tavares, J., Ribose 5-phosphate isomerase B knockdown compromises Trypanosoma brucei bloodstream form infectivity. PLoS Negl Trop Dis, 2015, 9, (1), e3430.

[264] Stern, A.L.; Burgos, E.; Salmon, L.; Cazzulo, J.J., Ribose 5-phosphate isomerase type B from Trypanosoma cruzi: kinetic properties and site-directed mutagenesis reveal information about the reaction mechanism. Biochem J, 2007, 401, (1), 279-285.

[265] Stern, A.L.; Naworyta, A.; Cazzulo, J.J.; Mowbray, S.L., Structures of type B ribose 5phosphate isomerase from Trypanosoma cruzi shed light on the determinants of sugar specificity in the structural family. FEBS J, 2011, 278, (5), 793-808.

[266] Jamdhade, M.D.; Pawar, H.; Chavan, S.; Sathe, G.; Umasankar, P.K.; Mahale, K.N.; Dixit, T.; Madugundu, A.K.; Prasad, T.S.; Gowda, H.; Pandey, A.; Patole, M.S., Comprehensive proteomics analysis of glycosomes from Leishmania donovani. OMICS, 2015, 19, (3), 157-170.

[267] Castro, H.; Teixeira, F.; Romao, S.; Santos, M.; Cruz, T.; Florido, M.; Appelberg, R.; Oliveira, P.; Ferreira-da-Silva, F.; Tomas, A.M., Leishmania mitochondrial peroxiredoxin plays a crucial peroxidase-unrelated role during infection: insight into its novel chaperone activity. PLoS pathogens, 2011, 7, (10), e1002325. 
[268] Teixeira, F.; Castro, H.; Cruz, T.; Tse, E.; Koldewey, P.; Southworth, D.R.; Tomas, A.M.; Jakob, U., Mitochondrial peroxiredoxin functions as crucial chaperone reservoir in Leishmania infantum. Proceedings of the National Academy of Sciences of the United States of America, 2015, 112, (7), E616-624.

[269] Gomez-Arreaza, A.; Acosta, H.; Quinones, W.; Concepcion, J.L.; Michels, P.A.; Avilan, L., Extracellular functions of glycolytic enzymes of parasites: unpredicted use of ancient proteins. Mol Biochem Parasitol, 2014, 193, (2), 75-81.

[270] Mani, M.; Chen, C.; Amblee, V.; Liu, H.; Mathur, T.; Zwicke, G.; Zabad, S.; Patel, B.; Thakkar, J.; Jeffery, C.J., MoonProt: a database for proteins that are known to moonlight. Nucleic acids research, 2015, 43, (Database issue), D277-282.

[271] Gonzalez, S.N.; Valsecchi, W.M.; Maugeri, D.; Delfino, J.M.; Cazzulo, J.J., Structure, kinetic characterization and subcellular localization of the two ribulose 5-phosphate epimerase isoenzymes from Trypanosoma cruzi. PLoS One, 2017, 12, (2), e0172405.

[272] Opperdoes, F.R.; Coombs, G.H., Metabolism of Leishmania: proven and predicted. Trends Parasitol, 2007, 23, (4), 149-158.

[273] Maugeri, D.A.; Cazzulo, J.J.; Burchmore, R.J.; Barrett, M.P.; Ogbunude, P.O., Pentose phosphate metabolism in Leishmania mexicana. Mol Biochem Parasitol, 2003, 130, (2), 117-125.

[274] Schenk, G.; Duggleby, R.G.; Nixon, P.F., Properties and functions of the thiamin diphosphate dependent enzyme transketolase. The international journal of biochemistry \& cell biology, 1998, 30, (12), 1297-1318.

[275] Veitch, N.J.; Maugeri, D.A.; Cazzulo, J.J.; Lindqvist, Y.; Barrett, M.P., Transketolase from Leishmania mexicana has a dual subcellular localization. Biochem J, 2004, 382, (Pt 2), 759-767.

[276] Creek, D.J.; Mazet, M.; Achcar, F.; Anderson, J.; Kim, D.H.; Kamour, R.; Morand, P.; Millerioux, Y.; Biran, M.; Kerkhoven, E.J.; Chokkathukalam, A.; Weidt, S.K.; Burgess, K.E.; Breitling, R.; Watson, D.G.; Bringaud, F.; Barrett, M.P., Probing the metabolic network in bloodstream-form Trypanosoma brucei using untargeted metabolomics with stable isotope labelled glucose. PLoS Pathog, 2015, 11, (3), e1004689.

[277] Clasquin, M.F.; Melamud, E.; Singer, A.; Gooding, J.R.; Xu, X.; Dong, A.; Cui, H.; Campagna, S.R.; Savchenko, A.; Yakunin, A.F.; Rabinowitz, J.D.; Caudy, A.A., Riboneogenesis in yeast. Cell, 2011, 145, (6), 969-980.

[278] McConville, M.J.; de Souza, D.; Saunders, E.; Likic, V.A.; Naderer, T., Living in a phagolysosome; metabolism of Leishmania amastigotes. Trends Parasitol, 2007, 23, (8), 368375.

[279] McConville, M.J.; Saunders, E.C.; Kloehn, J.; Dagley, M.J., Leishmania carbon metabolism in the macrophage phagolysosome- feast or famine? F1000Res, 2015, 4, (F1000 Faculty Rev), 938.

[280] Vince, J.E.; Tull, D.; Landfear, S.; McConville, M.J., Lysosomal degradation of Leishmania hexose and inositol transporters is regulated in a stage-, nutrient- and ubiquitindependent manner. Int J Parasitol, 2011, 41, (7), 791-800.

[281] Blangy, D.; Buc, H., [Allosteric transitions of phosphofructokinase of E. coli and phosphorylase B of rabbitmuscle]. Bull Soc Chim Biol (Paris), 1967, 49, (11), 1473-1478. 
[282] Newsholme, E.A.; Rolleston, F.S.; Taylor, K., Inhibition of brain hexokinase by glucose 6-phosphate. Biochem J, 1967, 104, (3), 47P.

[283] Newsholme, E.A.; Gevers, W., Control of glycolysis and gluconeogenesis in liver and kidney cortex. Vitam Horm, 1967, 25, 1-87.

[284] Ciou, S.C.; Chou, Y.T.; Liu, Y.L.; Nieh, Y.C.; Lu, J.W.; Huang, S.F.; Chou, Y.T.; Cheng, L.H.; Lo, J.F.; Chen, M.J.; Yang, M.C.; Yuh, C.H.; Wang, H.D., Ribose-5-phosphate isomerase A regulates hepatocarcinogenesis via PP2A and ERK signaling. Int $J$ Cancer, 2015, 137, (1), 104-115.

[285] Kabashima, T.; Kawaguchi, T.; Wadzinski, B.E.; Uyeda, K., Xylulose 5-phosphate mediates glucose-induced lipogenesis by xylulose 5-phosphate-activated protein phosphatase in rat liver. Proc Natl Acad Sci U S A, 2003, 100, (9), 5107-5112.

[286] Ivens, A.C.; Peacock, C.S.; Worthey, E.A.; Murphy, L.; Aggarwal, G.; Berriman, M.; Sisk, E.; Rajandream, M.A.; Adlem, E.; Aert, R.; Anupama, A.; Apostolou, Z.; Attipoe, P.; Bason, N.; Bauser, C.; Beck, A.; Beverley, S.M.; Bianchettin, G.; Borzym, K.; Bothe, G.; Bruschi, C.V.; Collins, M.; Cadag, E.; Ciarloni, L.; Clayton, C.; Coulson, R.M.; Cronin, A.; Cruz, A.K.; Davies, R.M.; De Gaudenzi, J.; Dobson, D.E.; Duesterhoeft, A.; Fazelina, G.; Fosker, N.; Frasch, A.C.; Fraser, A.; Fuchs, M.; Gabel, C.; Goble, A.; Goffeau, A.; Harris, D.; HertzFowler, C.; Hilbert, H.; Horn, D.; Huang, Y.; Klages, S.; Knights, A.; Kube, M.; Larke, N.; Litvin, L.; Lord, A.; Louie, T.; Marra, M.; Masuy, D.; Matthews, K.; Michaeli, S.; Mottram, J.C.; MullerAuer, S.; Munden, H.; Nelson, S.; Norbertczak, H.; Oliver, K.; O'Neil, S.; Pentony, M.; Pohl, T.M.; Price, C.; Purnelle, B.; Quail, M.A.; Rabbinowitsch, E.; Reinhardt, R.; Rieger, M.; Rinta, J.; Robben, J.; Robertson, L.; Ruiz, J.C.; Rutter, S.; Saunders, D.; Schafer, M.; Schein, J.; Schwartz, D.C.; Seeger, K.; Seyler, A.; Sharp, S.; Shin, H.; Sivam, D.; Squares, R.; Squares, S.; Tosato, V.; Vogt, C.; Volckaert, G.; Wambutt, R.; Warren, T.; Wedler, H.; Woodward, J.; Zhou, S.; Zimmermann, W.; Smith, D.F.; Blackwell, J.M.; Stuart, K.D.; Barrell, B.; Myler, P.J., The genome of the kinetoplastid parasite, Leishmania major. Science, 2005, 309, (5733), 436442.

[287] Brenchley, R.; Tariq, H.; McElhinney, H.; Szoor, B.; Huxley-Jones, J.; Stevens, R.; Matthews, K.; Tabernero, L., The TriTryp phosphatome: analysis of the protein phosphatase catalytic domains. BMC Genomics, 2007, 8, 434.

[288] Naula, C.; Parsons, M.; Mottram, J.C., Protein kinases as drug targets in trypanosomes and Leishmania. Biochim Biophys Acta, 2005, 1754, (1-2), 151-159.

[289] Cordeiro, A.T.; Thiemann, O.H., 16-bromoepiandrosterone, an activator of the mammalian immune system, inhibits glucose 6-phosphate dehydrogenase from Trypanosoma cruzi and is toxic to these parasites grown in culture. Bioorg Med Chem, 2010, 18, (13), 47624768.

[290] Luna, K.P.; Hernandez, I.P.; Rueda, C.M.; Zorro, M.M.; Croft, S.L.; Escobar, P., In vitro susceptibility of Trypanosoma cruzi strains from Santander, Colombia, to hexadecylphosphocholine (miltefosine), nifurtimox and benznidazole. Biomedica, 2009, 29, (3), 448-455.

[291] Ortiz, C.; Moraca, F.; Medeiros, A.; Botta, M.; Hamilton, N.; Comini, M.A., Binding Mode and Selectivity of Steroids towards Glucose-6-phosphate Dehydrogenase from the Pathogen Trypanosoma cruzi. Molecules, 2016, 21, (3), 368.

[292] Dardonville, C.; Rinaldi, E.; Barrett, M.P.; Brun, R.; Gilbert, I.H.; Hanau, S., Selective inhibition of Trypanosoma brucei 6-phosphogluconate dehydrogenase by high-energy intermediate and transition-state analogues. J Med Chem, 2004, 47, (13), 3427-3437. 
[293] Ruda, G.F.; Campbell, G.; Alibu, V.P.; Barrett, M.P.; Brenk, R.; Gilbert, I.H., Virtual fragment screening for novel inhibitors of 6-phosphogluconate dehydrogenase. Bioorg Med Chem, 2010, 18, (14), 5056-5062.

[294] Ruda, G.F.; Wong, P.E.; Alibu, V.P.; Norval, S.; Read, K.D.; Barrett, M.P.; Gilbert, I.H., Aryl phosphoramidates of 5-phospho erythronohydroxamic acid, a new class of potent trypanocidal compounds. J Med Chem, 2010, 53, (16), 6071-6078.

[295] Roos, A.K.; Burgos, E.; Ericsson, D.J.; Salmon, L.; Mowbray, S.L., Competitive inhibitors of Mycobacterium tuberculosis ribose-5-phosphate isomerase B reveal new information about the reaction mechanism. The Journal of biological chemistry, 2005, 280, (8), 6416-6422.

[296] Loureiro, I.; Faria, J.; Clayton, C.; Macedo-Ribeiro, S.; Santarém, N.; Roy, N.; Cordeiro-da-Siva, A.; Tavares, J., Ribose 5-Phosphate Isomerase B Knockdown Compromises Trypanosoma brucei Bloodstream Form Infectivity. PLoS neglected tropical diseases, 2015, 9, (1), e3430.

[297] Alsford, S.; Turner, D.J.; Obado, S.O.; Sanchez-Flores, A.; Glover, L.; Berriman, M.; Hertz-Fowler, C.; Horn, D., High-throughput phenotyping using parallel sequencing of RNA interference targets in the African trypanosome. Genome Res, 2011, 21, (6), 915-924.

[298] Mukherjee, A.; Boisvert, S.; Monte-Neto, R.L.; Coelho, A.C.; Raymond, F.; Mukhopadhyay, R.; Corbeil, J.; Ouellette, M., Telomeric gene deletion and intrachromosomal amplification in antimony-resistant Leishmania. Mol Microbiol, 2013, 88, (1), 189-202.

[299] Ortiz, C.; Larrieux, N.; Medeiros, A.; Botti, H.; Comini, M.; Buschiazzo, A., Expression, crystallization and preliminary $X$-ray crystallographic analysis of glucose-6phosphate dehydrogenase from the human pathogen Trypanosoma cruzi in complex with substrate. Acta Crystallogr Sect F Struct Biol Cryst Commun, 2011, 67, (Pt 11), 1457-1461.

[300] Delarue, M.; Duclert-Savatier, N.; Miclet, E.; Haouz, A.; Giganti, D.; Ouazzani, J.; Lopez, P.; Nilges, M.; Stoven, V., Three dimensional structure and implications for the catalytic mechanism of 6-phosphogluconolactonase from Trypanosoma brucei. J Mol Biol, 2007, 366, (3), 868-881.

[301] Kerkhoven, E.J.; Achcar, F.; Alibu, V.P.; Burchmore, R.J.; Gilbert, I.H.; Trybilo, M.; Driessen, N.N.; Gilbert, D.; Breitling, R.; Bakker, B.M.; Barrett, M.P., Handling uncertainty in dynamic models: the pentose phosphate pathway in Trypanosoma brucei. PLoS Comput Biol, 2013, 9, (12), e1003371.

[302] Phillips, C.; Dohnalek, J.; Gover, S.; Barrett, M.P.; Adams, M.J., A 2.8 A resolution structure of 6-phosphogluconate dehydrogenase from the protozoan parasite Trypanosoma brucei: comparison with the sheep enzyme accounts for differences in activity with coenzyme and substrate analogues. J Mol Biol, 1998, 282, (3), 667-681.

[303] Stoffel, S.A.; Alibu, V.P.; Hubert, J.; Ebikeme, C.; Portais, J.C.; Bringaud, F.; Schweingruber, M.E.; Barrett, M.P., Transketolase in Trypanosoma brucei. Mol Biochem Parasitol, 2011, 179, (1), 1-7.

\section{TABLES \& FIGURES}




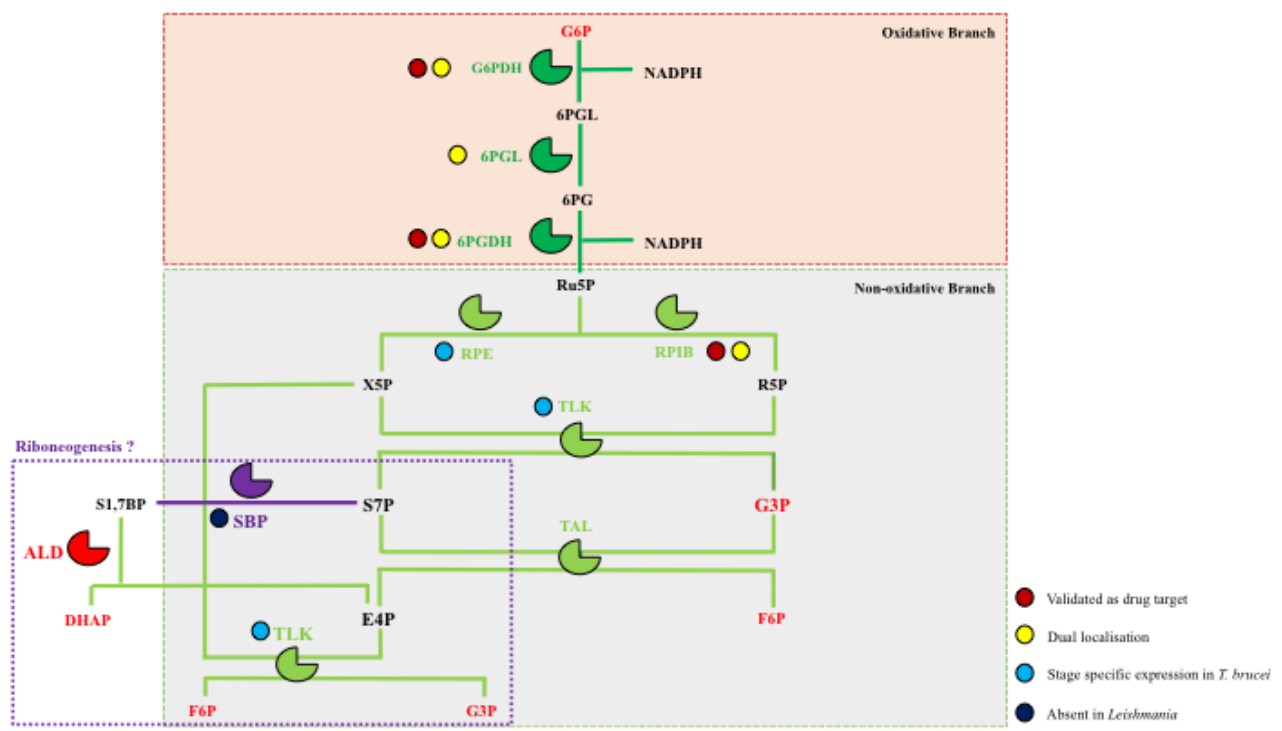

Figure 1. Pentose phosphate pathway in trypanosomatids. The enzymes of the oxidative and non-oxidative branch are depicted in dark and light green, respectively: G6PDH, glucose-6-phosphate dehydrogenase; 6PGL, 6phosphogluconolactonase; 6PGDH, 6-phosphogluconate dehydrogenase; RPIB, ribose-5-phosphate isomerase B; RPE, ribulose-5-phosphate epimerase; TKT, transketolase; TAL; transaldolase. Enzymes from glycolysis (ALD, aldolase) and riboneogenesis (SBP, sedoheptulose biphosphatase) are represented in red and purple, respectively. The oxidative PPP, non-oxidative PPP and riboneogenesis metabolic flow are depicted with dark green, light green and purple lines. Metabolites in red are generated in glycolysis. 6PG, 6-phosphogluconate; 6PGL, 6phsophogluconalactone; DHAP, dihydroxyacetone phosphate; E4P, erythrose-4-phosphate; F6P, fructose-6phosphate; G3P, glyceraldehyde-3-phosphate; G6P, glucose-6-phosphate; R5P, ribose-5-phosphate; Ru5P, ribulose-5-phosphate; S7P, sedoheptulose-7-phosphate; S1,7BP, sdoheptulose-1, 7-biphosphate; X5P, xylulose-5phosphate. The dashed purple line highlights riboneogenesis, which has not been formally demonstrated to operate in trypanosomes. The circles next to some enzymes indicate genetic validation by RNAi and/or gene knockdown has been performed in at least one of the three parasites (red), dual localisation between the cytosol and the glycosomes (yellow), expressed only in the insect-stage of $T$. brucei but not in bloodstream forms (light blue) or not encoded by Leishmania parasites (dark blue). Modified and updated from [243]. 
A
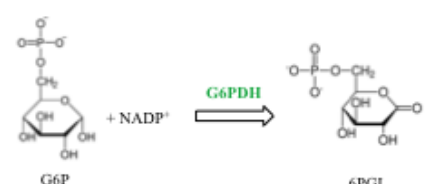

6PGL

B

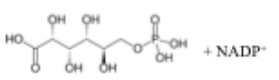

$6 \mathrm{PC}$
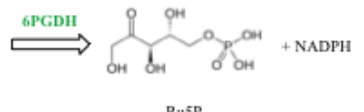

Ru5P

C

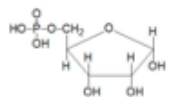

R5P

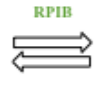

$\stackrel{\text { RPIB }}{\stackrel{2}{\rightleftarrows}}$

RuSP
$\int_{\mathrm{O}_{H}}^{\mathrm{OH}} \mathrm{O}_{\mathrm{OH}}^{\mathrm{OH}}$
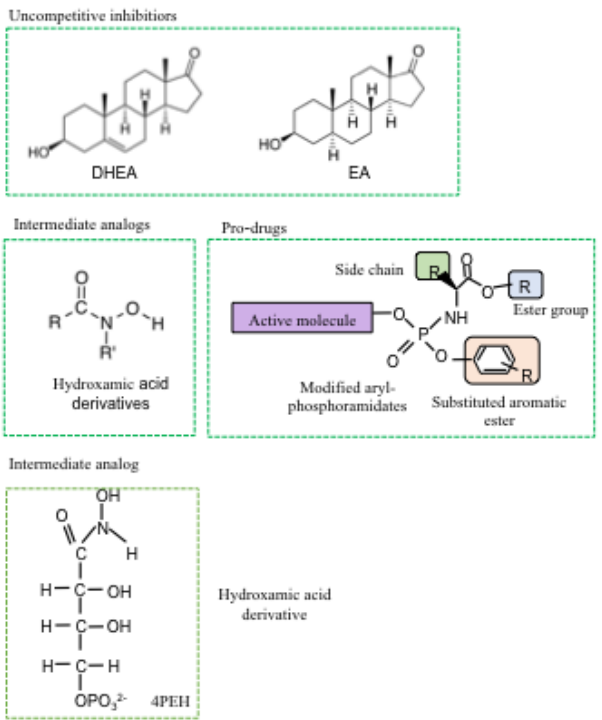

(1)

Figure 2. Available inhibitors of enzymes from the pentose phosphate pathway in trypanosomatids. A-B) On the left are represented the PPP enzymes and the reactions they catalyse and on the right the available inhibitors or classes of inhibitors. The enzymes of the oxidative and non-oxidative branch are depicted in dark and light green, respectively: G6PDH, glucose-6-phosphate dehydrogenase; 6PGDH, 6-phosphogluconate dehydrogenase; RPIB, ribose-5-phosphate isomerase B. Metabolites: 6PG, 6-phosphogluconate; 6PGL, 6-phosphogluconalactone; G6P, glucose-6-phosphate; R5P, ribose-5-phosphate; Ru5P, ribulose-5-phosphate. Inhibitors: DHEA, dehydroepiandrosterone; EA, epiandrosterone; 4PEH, 4-phospho-D-erythronate. For more detailed information [251, 264, 289-296]. 
Table 1. Essentiality data and crystal structure availability for PPP enzymes in T. brucei, T. cruzi and Leishmania spp.

\begin{tabular}{|c|c|c|c|c|c|c|}
\hline \multirow[t]{2}{*}{ Protein } & \multicolumn{3}{|c|}{ Essentiality data } & \multicolumn{3}{|c|}{ Crystal structure } \\
\hline & T. brucei & T. cruzi & Leishmania & T. brucei & T. cruzi & Leishmania \\
\hline $\begin{array}{l}\text { Glucose-6-phosphate } \\
\text { dehydrogenase }\end{array}$ & $\begin{array}{c}\text { Essential } \\
\text { [251] } \\
\text { Not essential } \\
\text { [297] }\end{array}$ & - & $\begin{array}{l}\text { Growth } \\
\text { defect } \\
{[298]}\end{array}$ & - & $\begin{array}{l}{[250,} \\
299]\end{array}$ & - \\
\hline Phosphogluconolactonase & $\begin{array}{l}\text { Not essential } \\
{[297]}\end{array}$ & - & 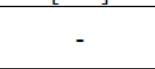 & {$[300]$} & - & - \\
\hline $\begin{array}{l}\text { Phosphogluconate } \\
\text { dehydrogenase }\end{array}$ & $\begin{array}{c}\text { Essential } \\
\text { [301] } \\
\text { Not essential } \\
\text { [297] }\end{array}$ & - & - & [302] & - & - \\
\hline $\begin{array}{c}\text { Ribose 5-phosphate } \\
\text { isomerase }\end{array}$ & $\begin{array}{l}\text { Growth defect } \\
{[263,297]}\end{array}$ & - & $\begin{array}{c}\text { Essential } \\
\text { [261] }\end{array}$ & - & {$[265]$} & - \\
\hline $\begin{array}{c}\text { Ribulose 5-phosphate } \\
\text { epimerase }\end{array}$ & $\begin{array}{c}\text { Not essential } \\
{[297]}\end{array}$ & - & {$[->]$} & - & - & - \\
\hline Transketolase & $\begin{array}{c}\text { Not essential } \\
{[303]}\end{array}$ & - & - & - & - & {$[275]$} \\
\hline Transaldolase & $\begin{array}{l}\text { Not essential } \\
\text { [276] }\end{array}$ & - & - & - & - & - \\
\hline
\end{tabular}

\section{GRAPHICAL ABSTRACT}

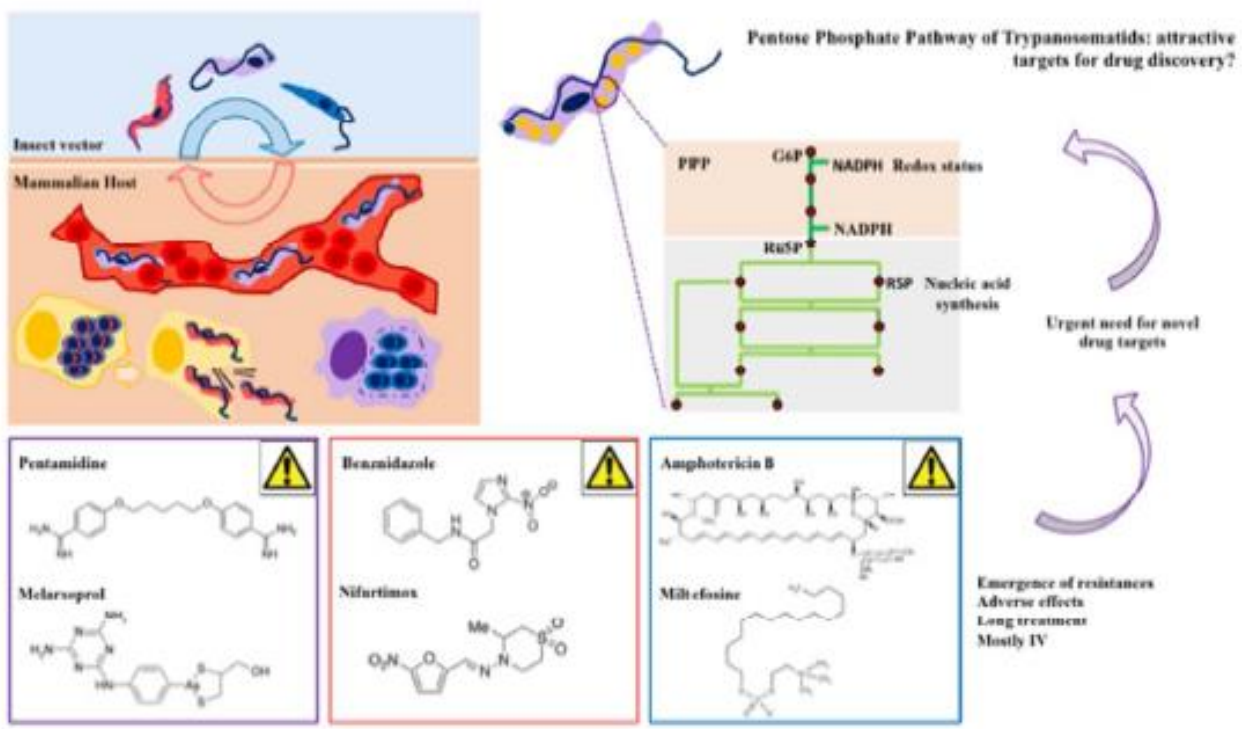

